\title{
Review Article \\ Human Urine Proteomics: Analytical Techniques and Clinical Applications in Renal Diseases
}

\author{
Shiva Kalantari, ${ }^{1}$ Ameneh Jafari, ${ }^{2}$ Raheleh Moradpoor, ${ }^{2}$ \\ Elmira Ghasemi, ${ }^{2}$ and Ensieh Khalkhal ${ }^{2}$ \\ ${ }^{1}$ Chronic Kidney Disease Research Center, Labbafinejad Hospital, Shahid Beheshti University of Medical Sciences, Tehran, Iran \\ ${ }^{2}$ Department of Basic Science, Faculty of Paramedical Sciences, Shahid Beheshti University of Medical Sciences, Tehran, Iran
}

Correspondence should be addressed to Shiva Kalantari; shiva.kalantari@sbmu.ac.ir

Received 20 July 2015; Accepted 9 November 2015

Academic Editor: Petra Zürbig

Copyright (C) 2015 Shiva Kalantari et al. This is an open access article distributed under the Creative Commons Attribution License, which permits unrestricted use, distribution, and reproduction in any medium, provided the original work is properly cited.

\begin{abstract}
Urine has been in the center of attention among scientists of clinical proteomics in the past decade, because it is valuable source of proteins and peptides with a relative stable composition and easy to collect in large and repeated quantities with a noninvasive procedure. In this review, we discuss technical aspects of urinary proteomics in detail, including sample preparation, proteomic technologies, and their advantage and disadvantages. Several recent experiments are presented which applied urinary proteome for biomarker discovery in renal diseases including diabetic nephropathy, immunoglobulin A (IgA) nephropathy, focal segmental glomerulosclerosis, lupus nephritis, membranous nephropathy, and acute kidney injury. In addition, several available databases in urinary proteomics are also briefly introduced.
\end{abstract}

\section{Introduction}

Clinical samples such as tissues and bio fluids (e.g., serum, plasma, urine, and saliva) are undoubtedly valuable sources in biomarker discovery studies for diagnostic proposes. The protein content complexity is the first issue in handling and analysis of such samples. As urine, which contains approximately 2000 proteins $[1,2]$ and is a less complex sample than plasma which contain more than 10,000 core proteins [3], could be collected in a noninvasive and unrestricted way, it is a preferable resource for investigation of a broad spectrum of diseases. Moreover, the protein composition and fragmentation of urine are relatively stable in comparison with other biofluids such as plasma or serum which are prone to proteolytic degradation during and after sampling [4].

As urine is the consequence of blood filtration and also contained all secreted proteins from tubules and kidney specific cells [5-10], it thus has been studied for investigating the pathological process of systemic as well as renal diseases [11]. Serum proteins are filtered based on their sizes and charges at the glomeruli [12] while reabsorption of abundant serum proteins such as albumin, immunoglobulin light chain, transferrin, vitamin D binding protein, myoglobin, and receptor-associated protein occurs in proximal renal tubules mainly by endocytic receptors, megalin, and cubilin [13-16]. Thus, protein concentration in normal donor urine is very low (less than $100 \mathrm{mg} / \mathrm{L}$ when urine output is $1.5 \mathrm{~L} /$ day), and normal protein excretion is less than $150 \mathrm{mg} /$ day. This is about a factor 1000 less compared with other body fluids such as plasma. Excretion of more than $150 \mathrm{mg} /$ day protein is defined as proteinuria and is indicative of glomerular or reabsorption dysfunction.

Urine proteomics studies account for several barriers such as low concentration of total protein, high concentration of salts and other ingredients that hinder protein separation [17], and high dynamics of changes in urine composition between different seasons of the material collection. Due to differences in sensitivity and availability of various proteomic techniques, considerable efforts have been made to find a suitable method to analyze the expression of specific urine marker proteins [18]. 
Urine proteomics is a powerful platform to identify urinary excreted proteins and peptides in different stages of disease or therapy and to determine their quantity, functions, and interactions [19]. Therefore, mechanism of the disease and novel therapeutic targets could be suggested by proteomic approaches. In this review we focus on technical aspects of analyzing urine proteome; application of this platform in clinic and also several urine proteome databases are reviewed.

\section{Normal Human Urinary Proteome}

Normal human urine contains a significant amount of peptides and protein. In 2004 nearly 1400 protein spots were separated by using two-dimensional gel electrophoresis (2DE) and 150 distinct proteins from 420 spots were identified by mass spectrometry [8]. This number of identified urinary proteins increased significantly to around 1534 in 2006 by combining one-dimensional gel electrophoresis and reverse phase liquid chromatography coupled to mass-spectrometry [1]. To date, over 2000 proteins in total are estimated in normal human urine of which 1823 proteins were identified by Marimuthu et al. in 2011 [20]. Identified proteins by Marimuthu et al. were $\sim 300$ greater than Adachi's report and hence could serve as a comprehensive reference list for future studies. Some of the urinary proteins have greater experimental molecular weights than the theoretically possible from amino acid sequence alone, indicating the presence of posttranslational modifications. $225 \mathrm{~N}$-glycoproteins [10] and 31 phosphoproteins [21] were identified in normal human urinary proteome. Normal human urine contains exosomes, small vesicles with diameters less than $100 \mathrm{~nm}$ that are secreted from renal epithelial cells.

Exosomes contain a number of disease related proteins. There are 1132 proteins in urinary exosomes including 14 phosphoproteins [22]. It is known that the urinary proteome differs between healthy individuals, particularly between men and women. In addition to the interindividual differences, the urinary proteome from the same individual varies at different time points due to the effect of exercise, diet, lifestyle, and other factors. The urinary proteome changes significantly over time. Urine collected in the morning contained more proteins than in the afternoon and evening. In addition, the interday proteome variation was observed to be greater than the variation at different time points in the same day [23].

\section{Urine Preparation}

Optimization of sample preparation is a necessary first step for urinary proteome analysis and sample desalting; that is, using precipitation or dialysis is often required. Several protocols that are used to isolate urinary proteins were employed using precipitation, lyophilisation, ultracentrifugation, and centrifugal filtration. Acetone precipitates more acidic and hydrophilic proteins. Ultracentrifugation fractionates more basic, hydrophobic, and membrane proteins. Organic solvents (90\% ethanol and $10 \%$ acetic acid) precipitate urinary proteins in the highest recovery rate. The ACN-precipitated urine sample produced the greatest number of spots on a two-dimensional (2D) gel, whereas the acetic-precipitated sample yielded the smallest number of spots [24]. The dialysis of urine proteins and concentration by lyophilisation without fractionation significantly improve reproducibility and resolution and are probably able to reflect total urinary proteins on 2D gels. In addition, the removal of albumin from the urine helps to identify the low abundant proteins [25]. Two main variables have been analyzed in urine preparation methods: quantity (protein recovery yield) and quality (2D spot patterns or proteomic profiles). The conclusions reached are that there is no single perfect protocol that can be used to examine the entire urinary proteome since each method has both advantages and disadvantages in comparison with the others. A combination of several sample preparation methods is required to obtain the greatest amount of quantitative and qualitative information [24].

\section{Urine Proteome Enrichment}

Due to the fact that disease specific biomarkers are likely in the low abundant fraction of proteome which are masked by high abundant proteins, enrichment strategies may increase the chance of capturing these potential biomarkers.

Depletion of high abundant proteins using chromatographic based enrichment methods or commercial kits specialized for urine samples are available strategies for enrichment.

Several high abundant proteins (e.g., albumin, transferrin, haptoglobin, immunoglobulin G, immunoglobulin A, and alpha-1 antitrypsin) could be removed using antibodybased affinity depletion approaches (e.g., multiple affinity removal system (MARS)) that are able to be coupled with either 2DE or LC-MS analysis [26, 27]. Enrichment of low abundant and depletion of high abundant proteins could be combined in peptide ligand library approach. In this method a diverse library of peptides immobilized on a solidphase chromatographic matrix interact with the specific recognition site of proteins. Captured proteins, therefore, are included in the analysis procedure while other proteins without suitable interaction are washed out and excluded. Saturation of peptides for high abundant proteins leads to decrease in their concentration in the final eluent. In addition, concentrated low abundant proteins on their specific ligands result in decreasing the dynamic range of proteins in the specimen [28]. The success of this method depends on using high amounts of initial material; otherwise, the enriched profile would be similar to the nonenriched original profile [29]. Chromatography techniques such as ion-exchange, sizeexclusion, and affinity chromatography are widely used for enrichment or depletion purposes; however, they are also applicable for fractionation and separation prior to MS (see Section 5.2).

Charge-charge interaction between proteins of the sample and charged column is the base of capturing subproteome in ion-exchange chromatography. In anion exchange chromatography, negatively charged proteins or peptides interact with positively charged column and gradually eluted off the column by a mobile phase with gradient of salt solution. Majority of bound proteins with negative charge are eluted 
at the highest ionic strength [30]. Lu et al. enriched lowabundance proteins in urine specimen using this technique and observed improved number of identification in 2DE map of enriched samples in comparison with the map of nonenriched samples [30].

In contrast to anion exchange, charge of stationary phase in strong cation exchange chromatography (SCX) becomes negative in aqueous solution and therefore interacts with strongly basic analytes. To elute the analytes, column is then washed with a solvent with $\mathrm{pH}$ gradient. The most cationic proteins/peptides would elute off the column at higher $\mathrm{pH}$. Therefore, this technique has been introduced as a suitable method for phosphoproteome enrichment [31]. Thongboonkerd et al. showed application of SCX for enrichment of the basic/cationic urinary proteome [32].

Commercial protein depletion kits are currently available that some of them have been optimized for proteomic studies on urine samples (e.g., UPCK urine protein enrichment/concentration kit). According to the literature using these depletion kits could improve the number of lowabundance proteins identified in urine up to 2.5-fold [33].

Selection of the enrichment strategy depends on the aim and specific study requirements.

\section{Techniques for Urinary Proteomic Studies}

Common techniques for urinary proteome analysis are twodimensional gel electrophoresis followed by mass spectrometry (2DE-MS), liquid chromatography coupled to mass spectrometry (LC-MS), surface enhanced laser desorption/ionization coupled to mass spectrometry (SELDI-TOF), and capillary electrophoresis coupled to mass spectrometry (CE-MS) and protein microarrays [34].

5.1. DE-MS. Two-dimensional gel electrophoresis is a robust and widely used method for protein separation. In this technique proteins are separated based on their isoelectric point and molecular mass, visualized, and semiquantified by staining [25]. Advantages of 2DE include ability to detect relatively large molecules, estimate molecular weight and pI of proteins, and investigate posttranslational modifications [35]. Common limitations of 2DE technique are requirements for high protein amount, lack of automation, loss of extremely acidic $(\mathrm{pH}<3)$ or basic proteins $(\mathrm{pH}>10)$, lack of detection for large $(\mathrm{Mr}>150 \mathrm{kD})$ and small $(\mathrm{Mr}<10 \mathrm{kD})$ proteins and hydrophobic proteins, and lack of reproducibility, lowthroughput capacity, and narrow dynamic range [36, 37]. A few of these limitations have been granted by some technical improvements. Development of two-dimensional difference gel electrophoresis (2D-DIGE) ameliorated problem of lowthroughput capacity improve the quantification accuracy and statistical confidence by use of internal standard and pooling samples labeled with different fluorescent dyes (Cy2, Сy3, and Cy5) [38]. Blue native technique was developed in order to specify investigations on hydrophobic proteins, protein complexes, and protein-protein interactions on the gel matrix [39]. Blue native technique separates proteins based on their molecular weights on two dimensions. The reproducibility problem has been minimized using precast gels with multirun gel tanks which are capable of running several electrophoretic gels simultaneously. Furthermore, staining gels with different fluorescent dyes postelectrophoretically increase the sensitivity of detection spots. In case of study the urinary proteins by $2 \mathrm{DE}$, desalting by chromatographic columns or filters is recommended to obtain well separated spots on the gel. Despite improvement in 2DE technique, lack of automation and time consuming steps (approximately 3 days for obtaining a 2DE pattern) lead to decrease inclination of researchers for applying this technique in their recent experiments.

5.2. LC-MS. Liquid chromatography (LC) is a high resolution separation method that employs one or more inherent characteristics of a protein, its mass, isoelectric point, hydrophobicity, or biospecificity [40]. This method separates large amounts of analytes (protein/peptides) on HPLC column or small amount of analytes (peptides) on a capillary LC column with high sensitivity and can be automated [41]. LC/MS can identify low-abundance and hydrophobic proteins not seen by $2 \mathrm{DE}$ and thus is considered a complementary method for $2 \mathrm{DE}$ in proteomics $2 \mathrm{D}$ liquid phase fractionation and can be used for in-depth analysis of body fluids such as urine [42]. A combination of gel and different steps of gel-free techniques (i.e., sequential separation using different matrices in two or more independent steps) is used for a better separation and referred to as Mud PIT. Strong cation exchange column (SCX) is a good choice for separate urinary peptides before injection to reverse phase columns coupled to MS. The retention times of many urinary compounds including organic acids and bile salts overlap with peptides in reverse phase LC which can be removed using SCX column [43]. Recently, weak anion exchange columns are used for fractionation and enrichment of low abundant proteins excreted in the urine prior to $2 \mathrm{DE}$ [44]. This combination method has potential for identification of low abundant biomarkers but still has challenges for identification of isoforms and PTMs. Affinity chromatography columns before LC-MS runs are the other alternative methods for capturing subproteomes from the urine such as glycoproteome and phosphoproteome $[22,45]$. LC technique can be coupled with diverse types of mass spectrometry instruments that affect the accuracy and confidence of identification and quantification.

The high resolution instruments such as the Fourier transform ion cyclotron resonance (FTICR) and orbitrap or hybrid and tribrid instruments such as Q-exactive (hybrid of quadrupole and orbitrap) and orbitrap Fusion (tribrid of quadrupole, orbitrap, and linear ion trap) may couple to LC for clinical sample analysis including urine. Kalantari et al. and Adachi et al. analyzed urine samples from IgA nephropathic patients and normal human urine, respectively, using LC coupled with high resolution MS instruments [1, 46]. Proteins separated by LC could be quantified with the labeling (e.g., stable isotope affinity tag and isobaric tags) and label-free techniques [41]. Quantification of proteins or peptides in large scale is possible only by gel-free MS based methods which is considered an advantage for these techniques. As LC-MS is time-consuming and sensitive towards interfering compounds (e.g., salts) and precipitation 
of analytes on column materials, it is not applicable yet for routine clinical diagnostic tests [48].

5.3. SELDI-TOF. Surface-enhanced laser desorption/ionization time of flight (SELDI-TOF) technology uses protein-chip arrays with different properties on the surface (hydrophilic or hydrophobic materials, cationic or anionic matrices, lectin, or antibody affinity reagents) coupled with a TOF mass spectrometer [36]. Proteins or peptides of interest are bound to the active surface depending on the surface property while unwanted unbound proteins are washed away with an appropriate solvent or buffer $[36,49]$. It is a widely used method in clinical proteomics that can detect different protein expression patterns of body fluid and tissue specimens between patients and healthy subjects and thus is a powerful tool for biomarker discovery [50]. SELDI-TOF is a high throughput and easy to use technique that can be automated. In addition, a low sample volume $(<10 \mu \mathrm{L})$ without prior concentration or precipitation of proteins is required $[42,51]$. However, it has some limitations such as difficulties in standardization since the proteome profiles generated by SELDI are influenced by many factors such as the type of surface coating, $\mathrm{pH}$, salt condition, and protein concentration. Other limitations of SELDI are lack of reproducibility, restriction to selected proteins, low-resolution mass spectrometer, and lack of a sequence based identification of the resolved peaks $[48,52,53]$.

5.4. CE-MS. Capillary electrophoresis coupled to MS represents ideal analytical technique for different omics approaches that provides high resolution protein separation based on differential migration through a buffer-filled capillary column in an electrical field (300 to $500 \mathrm{~V} / \mathrm{cm}$ ) $[54,55]$. CE can be coupled either with MALDI (off-line) or ESI (on-line). While data analysis of CE-MALDI is more sight forward, signal suppression and variability results from matrix effect as well as loss of resolution are considered challenges in this method and thus coupling with ESI is preferred [56]. Though CE is capable of being coupled with any type of MS instrument, ESI-FT-ICR is the most applicable one for identification of proteins and peptides disease biomarkers in urine [47, 57]. CE-MS offers several advantages including fast and high efficient separation, selectivity, sensitivity, low cost, absence of buffer gradients, capability of fast reconditioning with $\mathrm{NaOH}$, and insensitivity towards precipitating proteins peptides, lipids, and other compounds that often interfere with LC-separation $[51,58]$.

This method is especially applicable for analysis of the low molecular weight $(<20 \mathrm{kDa})$ molecules. Its disadvantages are limited capacity to separate high molecular weight proteins $(>20 \mathrm{kDa})$ and low-abundance proteins, lack of reproducibility and robustness, and small sample loading capacity $[53,55]$.

5.5. Protein Microarrays. Protein microarrays (or protein chips) are miniaturized solid-phase ligand-binding assay systems using immobilized antibodies or antigens on a support surface, generally a slide or membrane [59]. According to different features, such as content, surface, or detection system, there are many types of protein microarrays [60]. Main advantages of protein microarrays include high-throughput; sensitivity and discovery of low molecular weight markers make them an ideal approach for urinary proteomics. However, microarrays have several limitations such as requirement for a highly specific probe for each analyte, low density coverage that allows detection of only a few proteins, variable specificity, and lack of detection of posttranslational modifications $[25,61]$.

\section{Advances in Urine Proteomic Research}

Over the last two decades, advances in proteomic tools have been impressive. "Microfluidic chip CE (MC-CE) device," a recent analyzing tool for biomarker discovery, is one of the precious advances that enabled profiling of urinary markers with adjustable on-chip sample dilution [62]. This device is specially suitable for detection of urine anionic biomarkers and has high separation efficiency and sensitivity in analyte detection. It is composed of two units: sample dilution and on-chip CE separation [63]. In this device sequence dilution and separation are applicable by magnetic fluid activated valves. Recent studies on urine samples using microfluidic devices have been reviewed by Lin et al. [64].

Filter aided sample preparation (FASP), a method of detergent depletion, is one of the effective recent technique in shotgun proteomic analysis [65]. This method benefits from the advantages of both in-gel and in-solution digestion and has high protein coverage [66].

Low volume of sample is required and feasibility of digesting protein mixtures directly on the filter membrane is the most important advantages of this method.

96-well based parallel FASP is a robust method in urine proteomics which is cost-effective, repeatable, and efficient. Wiśniewski et al. and Yu et al. [65, 66] have applied this technique successfully for analyzing urine samples.

Advances in quantification methods provide more information from peptides and proteins in biological samples including urine. In label-free quantification the main goal is to develop the software with capability of normalization and reduced errors originated from instrument and loading samples. "Quanti" is a right example of recently developed software which is capable of relatively accurate label-free quantification of proteins with correction of responses to instrumental fluctuation [67]. This software has been applied in several studies on urine proteomics [46, 68-71]. MaxLFQ is also newly developed label-free software that can handle very large experiments, uses delayed normalization which makes it compatible with different separation procedures, and extracts the maximum ratio information from peptide signals [72]. Other label-free software programs and advantages and limitations of this technique have been reviewed elsewhere $[73,74]$.

Labeling techniques for quantification seems to be less improved during recent years in competition with label-free quantification techniques. However, isobaric tags for relative and absolute quantification (iTRAQ) as a versatile labeling technique which developed early in 2000s decade are still popular and frequently used specially in urine proteomics studies [75]. 


\section{The Use of Urine in Clinical Proteomics}

A major challenge in clinical proteomics is the identification of reliable biomarkers that help early diagnosis of disease and contribute to the development of personalized medicine. As $70 \%$ of urinary proteins stem from kidney and urinary tract and $30 \%$ originate from the other organs that are secreted into the blood circulation, study of the urinary proteomics could be useful in better understanding of pathophysiological mechanisms and the discovery novel biomarkers and therapeutic targets of kidney and nonkidney diseases [76]. Anderson et al. reported the identification of several proteins as urinary biomarkers in 1979. The explanation of disease-specific biomarkers in the urine is complicated by significant changes in urinary proteome during the day under the influence of some factors such as exercise, variations in the diet, and circadian rhythms. Simply comparing the proteome urine of patients with a particular disease with healthy individuals to distinguish between different diseases with similar symptoms is inadequate. Since the variability of conditions and irrelevant differences between healthy people and target diseased group are inevitably large and uncontrolled, comparison of one or more symptomatic similar diseases but different in etiology and severity simultaneously as controls is recommended for biomarker discovery. Thus, careful experimental design is the key to success in biomarker studies. Another issue is the correct matching of case and control groups. For instance, since some diseases such as cancer and chronic kidney disease usually occur in middleaged and elderly people, urine samples from young volunteers are not appropriate controls for studying these diseases. Urine proteomics, if observing the careful study design, is the promising platform for identification of early detection and noninvasive biomarkers in the new era of modern medicine.

Despite large number of studies published in the past decades using proteomic tools in biomarker discovery field, still no reliable, specific, sensitive biomarker is available. A general shortcoming of biomarker research is lack of reproducibility and effect of unknown factors originates from dark side of disease pathogenesis which we do not have enough knowledge about and therefore could not be controlled. This concern will be fade in the future by advances in preparation methods, separation procedure, and extended databases. In addition, following a comprehensive workflow in clinical proteomics from initial discovery to translation into a clinically useful assay would help a biomarker to be meaningful and applicable in the clinic. Mischak et al. defined six steps for this workflow: (I) initial identification and verification, (II) evaluation the results by a knowledgeable independent panel of experts, (III) evaluation in suitable biobank samples or newly collected samples, (IV) evaluation in clinical trial, (V) implementation in clinical practice, and (VI) proving the cost-effectiveness of validated biomarker [77].

Another important point that should be considered in the context of biomarker implementation in clinics is the use of a panel of biomarkers instead of a single biomarker. A panel of biomarkers can lead to increase sensitivity and accuracy of assays.

\subsection{Urinary Biomarkers in Renal Disease}

7.1.1. Diabetic Nephropathy. Diabetic nephropathy (DN) is a serious complication of diabetes with a complex etiology that involves up to $40 \%$ of diabetic patients $[39,43]$. DN is diagnosed by excretion of $30-300 \mathrm{mg}$ protein in the urine per 24 hours (microalbuminuria) which can progress to macroalbuminuria ( $>300 \mathrm{mg} / 24 \mathrm{~h}$ ) and/or changes in serum creatinine indicating decline in the glomerular filtration rate. The histological presentations of DN are loss of podocytes, thickness in glomerular basement membrane, proliferation of mesangial cells, and tubule interstitial fibrosis [44]. The current diagnostic tool for DN is biopsy that is invasive and not recommended for all suspicious cases due to its consequences. Urinary diagnostic biomarkers are promising noninvasive diagnostic molecules complementary to biopsy that will enter into the clinic in the near future. These diagnostic molecules can either promote the accurate diagnosis or decision for a more effective treatment.

Microalbuminuria (MA) is important for early diagnosis of DN and is the best predictor of DN available in the clinic [46]. However, several studies have shown that only a subset of patients with MA progress to proteinuria [47, 56]. Moreover, many individuals with type 1 diabetes have already experienced early renal function decline before or accidental with the onset of MA. So, it seems that MA may be an inadequate early diagnostic biomarker of DN (however, it may be appropriate for diagnosis of advanced $\mathrm{DN}$ ) and discovery of new sensitive and specific markers by proteomic techniques is necessary [76]. In addition, some of the suggested biomarkers for DN have been achieved on samples from patients whose disease was diagnosed by clinical criteria and not confirmed by biopsy which is highlighted necessity of more accurate studies on biomarker discovery for DN. The study of Soldatos and Cooper [44] was a well-designed pioneer pilot study for profiling the urine proteome of DN patients using SELDI-TOF for discovery of early diagnostic markers. They could identify a 12-peak urine protein signature in type 2 diabetic patients compared with healthy controls with $93 \%$ sensitivity and $86 \%$ specificity. Interestingly, patients in their study were normalbuminuric (albumin-to-creatinine ratio $<30 \mathrm{mg} / \mathrm{g}$ ) without renal dysfunction. In a case-control study Rossing using highresolution two-dimensional gel electrophoresis separation and protein identifications by MALDI-TOF-MS and LCMS/MS analysis [43] reported correlation between level of a set of proteins, in particular Tamm-Horse fall urinary glycoprotein (THP) and zinc- $\alpha$-2 glycoprotein (ZA2G), and the state of diabetic progressing in diabetic patients type 1 . Jim et al. using ELISA indicated that nephrinuria is detectable in all of type 2 diabetic patients with macroalbuminuria and microalbuminuria and thus nephrine has potential to be a new early biomarker of DN [78]. Capillary electrophoresiscoupled mass spectrometry was used to profile urine proteome of DN patients in a longitudinal study. Altered content of collagen fragments was suggested as a potential early detection biomarker which occurs 3-5 years before onset of macroalbuminuria [79]. 
TABLE 1: Putative biomarkers for diabetic nephropathy discovered in urine proteome analysis.

\begin{tabular}{|c|c|c|c|c|c|}
\hline Protein biomarkers & Up/downregulation & Cohort & Technique & Type of biomarker & Reference \\
\hline $\begin{array}{l}\text { Pancreatic amylase } \\
\text { deoxyribonuclease I }\end{array}$ & $\downarrow$ & $\begin{array}{l}\text { Healthy controls }(n=27) \text { and } \\
\text { diabetic patients }(n=27)\end{array}$ & $\begin{array}{l}\text { 8-plex } \\
\text { iTRAQ }\end{array}$ & Diagnostic & {$[80]$} \\
\hline CD36 & $\uparrow$ & $\begin{array}{c}\text { Type } 2 \text { diabetes }(\mathrm{T} 2 \mathrm{DM}) \text { with } \\
\text { normoalbuminuria }(n=20) \text { and } \\
\text { T2DM with microalbuminuria } \\
(n=20) \text { and T2DM with } \\
\text { macroalbuminuria }(n=20)\end{array}$ & ELISA & Prognostic & {$[118]$} \\
\hline Podocyte-secreted Angptl4 & $\uparrow$ & Diabetic rats & ELISA & $\begin{array}{l}\text { diagnostic and } \\
\text { therapeutic } \\
\text { biomarker }\end{array}$ & [119] \\
\hline $\begin{array}{l}\text { Gelsolin and } \\
\text { antithrombin-III }\end{array}$ & & & $\begin{array}{l}\text { GeLC- } \\
\text { MS/MS }\end{array}$ & Diagnostic & {$[120]$} \\
\hline $\begin{array}{l}\text { Ephrin type-B receptor } 4 \text { and } \\
\text { vitamin K-dependent } \\
\text { protein } Z\end{array}$ & & & $\begin{array}{l}\text { GeLC- } \\
\text { MS/MS }\end{array}$ & Prognostic & {$[120]$} \\
\hline AMBP, MLL3, and VDAC1 & & & LC-MS/MS & Diagnostic & {$[121]$} \\
\hline Fetuin-A & $\uparrow$ & DN patients $(n=85)$ & $\begin{array}{c}\text { Lectin } \\
\text { microarray }\end{array}$ & Prognostic & {$[122]$} \\
\hline $\begin{array}{l}\text { Collagen fragments } \\
\text { (specially collagen } \alpha-1(\mathrm{I}) \\
\text { chain) }\end{array}$ & $\downarrow$ & DN patients $(n=35)$ & CE-MS & Diagnostic & {$[79]$} \\
\hline
\end{tabular}

The most recent report of protein biomarkers for the stages of DN using iTRAQ suggested a diminished excretion of pancreatic amylase and deoxyribonuclease I [80]. Some of the novel urinary biomarkers for DN reporting in the last two years are tabulated in Table 1.

As biopsy is not performed in all patients suffering from diabetes (due to its invasiveness), DN is diagnosed based on clinical manifestations in some cases and, therefore, treated based on available guideline for DN. Nevertheless, interestingly, kidney injury in some of diabetic patients would not be a result of diabetic nephropathy and other kidney diseases such as membranous nephropathy or focal segmental glomerulosclerosis might also occur in diabetic patients which could not be diagnosed only by clinical manifestations. Therefore, biomarkers sensitive and specific for DN are undoubtedly needed as a noninvasive alternative of kidney biopsy.

7.1.2. IgA Nephropathy. IgA nephropathy (IgAN) is the most common type of glomerulonephritis worldwide that is characterized at biopsy by histological features including mesangial immunodeposits of IgA1 (by immune fluorescence) in association with C3 and IgG or IgM or both [81, 82]. The clinical presentation of IgAN is variable and could be a spectrum of clinical features from asymptomatic hematuria to rapidly progressive glomerulonephritis. Urinary excretion of relevant proteins such as immunoglobulin, cytokines, and complement factor suggest a promising new possibility in the search for noninvasive diagnostic markers in patients with IgAN.

SELDI-TOF as one of the powerful techniques in urinary proteomics was used by some research groups for biomarker discovery of IgAN. Rocchetti et al. analyzed urine proteome of 49 IgA nephropathy patients, 42 CKD (chronic kidney disease) patients, and 40 healthy individuals using this technique followed by MALDI-TOF for identification of differentially proteins and reported Perlecan laminin G-like 3 peptide and $\operatorname{Ig} \kappa$ light chains as indicator of disease activity [83].

Julian et al. applied CE-MS for detection of urinary polypeptide biomarkers differentiated patients with $\operatorname{IgA}$ nephropathy from other renal diseases including diabetic nephropathy, lupus nephritis, hypertensive renal disease, acute vasculitis with nephritis, and amyloidosis and from subjects with a functional renal allograft [84]. Some of these markers were identified by top-down MS/MS approach (e.g., alpha-1-antitrypsin, collagen type III alpha-1 chain, and uromodulin). In addition, they defined a panel of biomarkers named "Renal Damage Pattern" by comparing pattern obtained from healthy controls and several renal diseases. These markers then correlated with IgA nephropathy pattern using SDS-PAGE/western blotting.

Zhao et al. for first time used SILAC-labeled mouse serum as internal standard for human and urine proteome analysis by IEF-LC-MS/MS. They compared urine from IgAN patients treated and untreated and reported fifty-three peptides that were different between two groups. The authors could find novel candidates like ApoA1 and insulin-like growth factorbinding protein 7 (IGFBP7) for IgAN by this quantitation strategy [85]. Kalantari et al. in a pilot study on urine samples from 13 patients with $\operatorname{IgA}$ attempted to find a correlation between proteome data and pathological presentation used for classification of IgAN in biopsy through a high resolution mass spectrometry [46]. They performed two independent proteomic procedures (nano-LC-MS/MS and GeLC-MS/MS) 
TABLE 2: Putative biomarkers for IgAN discovered by urine proteome analysis.

\begin{tabular}{|c|c|c|c|c|c|}
\hline Protein biomarkers & Up/downregulation & Cohort & Technique & $\begin{array}{c}\text { Type of } \\
\text { biomarker }\end{array}$ & Reference \\
\hline GP2, vasorin, and EGF & $\downarrow$ & $\begin{aligned} \text { Healthy controls }(n=8) \\
\text { and gAN patients }(n=13)\end{aligned}$ & Nano-LC-MS/MS & Diagnostic & [86] \\
\hline $\begin{array}{l}\text { CLM9, protocadherin, } \\
\text { uteroglobin, DDPIV, } \\
\text { NHLC3, and SLAF5 }\end{array}$ & $\uparrow$ & $\begin{array}{l}\text { Healthy controls }(n=8) \\
\text { and IgAN patients }(n=13)\end{array}$ & Nano-LC-MS/MS & Diagnostic & {$[86]$} \\
\hline MBL & $\uparrow$ & $\begin{array}{l}\text { IgAN patients }(n=62) \text { and } \\
\text { control }(n=50)\end{array}$ & ELISA & Diagnostic & {$[87]$} \\
\hline sTfR & $\uparrow$ & $\begin{array}{l}\text { IgAN patients }(n=71) \text { and } \\
\quad \text { control }(n=50)\end{array}$ & $\begin{array}{c}\text { Latex-enhanced } \\
\text { immunonephelometric } \\
\text { assay }\end{array}$ & Diagnostic & [88] \\
\hline $\begin{array}{l}\text { Albumin fragments, } \\
\alpha \text {-1-antitrypsin, and } \alpha-1-\beta \text { - } \\
\text { glycoprotein }\end{array}$ & $\uparrow$ & $\begin{array}{l}\text { IgAN patients }(n=43) \text { and } \\
\quad \text { control }(n=50)\end{array}$ & $\begin{array}{l}\text { 2DE-MALDI-TOF-TOF } \\
\text { and ELISA }\end{array}$ & Prognostic & [123] \\
\hline LG3 & $\downarrow$ & $\begin{array}{l}\text { IgAN patients }(n=43) \text { and } \\
\text { control }(n=50)\end{array}$ & $\begin{array}{l}\text { 2DE-MALDI-TOF-TOF } \\
\text { and ELISA }\end{array}$ & Diagnostic & {$[123]$} \\
\hline
\end{tabular}

and reported a panel of candidates as prognostic markers including afamin, leucine-rich alpha-2-glycoprotein, ceruloplasmin, alpha-1-microgolbulin, hemopexin, apolipoprotein A-I, complement C3, vitamin D-binding protein, beta-2microglobulin, and retinol-binding protein 4 . The recent study on IgAN with a cohort of 30 patients and 30 controls suggested 18 differential urinary proteins separated and identified by IEF/LC-MS/MS [86]. Most of these reported candidates were complement components, coagulation factors, and extracellular and intracellular matrix and transmembrane. Table 2 shows some of the recent (last 3 years) reported urinary markers for IgAN.

7.1.3. Focal Segmental Glomerulosclerosis. Focal segmental glomerulosclerosis (FSGS) is a glomerular podocytopathy characterized by massive proteinuria as clinical manifestation and glomerular scaring as histological feature [87, 88]. hypoalbuminemia, hypercholesterolemia, and peripheral edema are associated with proteinuria and considered also clinical manifestations [87]. It is a complex disease categorized as primary $(\sim 80 \%)$ or secondary $(\sim 20 \%)$ based on the etiology. Diffuse foot process effacement of podocytes is mostly associated with primary form detected by electron microscopy [88]. Increasing frequency of FSGS in the past 20 years with $50 \%$ ESRD rate during 5-8 years from the time of diagnosis in resistant patients to therapy $[88,89]$ indicates the need of biomarkers for early diagnosis and prediction of responsiveness. Molecular biomarkers are helpful not only in diagnosis but even in understanding the pathogenesis and disease mechanism.

Shui et al. performed a classic proteomic study on urinary biomarkers FSGS mouse model [90]. Serial urine samples was collected on days $0,4,7,11,15$, and 20 and analyzed by two-dimensional electrophoresis followed by MALDI-TOFMS. They identified 37 proteins changed during the disease course and confirmed few of them via western blot. Collagen IV fragment, glutathione S-transferase, and E-cadherin were suggested as candidates for disease progression. The other candidates for early diagnosis identified in their study are tabulated in Table 3.

Wang et al. also studied biomarkers to distinguish between adriamycin nephropathy and Thyl.1 glomerulonephritis in the rat model [10]. Urine proteome was precipitated by acetone and, after protein concentration determination, equal urine proteome from each five sample pooled in four groups and subjected to lectin enrichment. LC-MS/MS analysis on eluted glycoproteome followed by quantification using spectral counting approach resulted in 46 differential proteins including Ig lambda-2 chain $\mathrm{C}$ region, protein YIPF3, hemopexin precursor, and 35 other proteins with different direction of changes and serum albumin precursor, isoform 1 of serotransferrin precursor, alpha-1-antiproteinase precursor, T-kininogen 1 precursor, trefoil factor 3 precursor, superoxide dismutase, and urinary protein 1 precursor with similar direction of changes.

SELDI technique was applied by Woroniecki et al. to identify different pattern in urine proteome of healthy control and steroid resistant (SRNS) and steroid sensitive (SSNS) patients with nephrotic syndrome such as MCD and FSGS [91]. Predictive models were constructed by supervised algorithm to differentiate between control and diseased (combination of SSNS and SRNS) and between SSNS and SRNS. Generated model for responsiveness prediction had 100\% accuracy and resulted in a differential protein of mass of 4,144 daltons with significant changes as the most important classifier.

Zhao et al. recently performed a study on urine biomarkers which reflect dynamic changes during disease course, analyzed by UPLC coupled with triple-TOF-MS, quantified by label-free quantification, and confirmed by western blot [92]. They examined six stages in ADR-induced rats. Relative abundance of twelve proteins showed an overall increasing trend while nine proteins shared an overall decreasing trend. Fetuin-B and B2-microglobulin changed at the early stage. These markers were further investigated to find human orthologues. Confirmed suggested candidates are shown in Table 3. 
TABLE 3: Putative biomarkers for focal segmental glomerulosclerosis discovered in urine proteome analysis.

\begin{tabular}{|c|c|c|c|c|c|}
\hline Protein biomarkers & Up/downregulation & Cohort & Technique & $\begin{array}{c}\text { Type of } \\
\text { biomarker }\end{array}$ & Reference \\
\hline Collagen IV, cadherin & $\downarrow$ & $\begin{array}{c}\text { AD-treated mice }(n=6) \\
\text { and normal control }(n=6)\end{array}$ & $\begin{array}{l}\text { 2DE-MS validated by } \\
\text { western blot }\end{array}$ & Prognostic & [90] \\
\hline Glutathione S-transferase & $\uparrow$ & & $\begin{array}{l}\text { 2DE-MS validated by } \\
\text { western blot }\end{array}$ & Prognostic & {$[90]$} \\
\hline $\begin{array}{l}\text { ADAM32, Cerberus, } \\
\text { apoptosis-inducing } \\
\text { factor-2, and Annexin A1 }\end{array}$ & $\uparrow$ & & & Diagnostic & {$[90]$} \\
\hline Tomoregulin & $\downarrow$ & & & Diagnostic & {$[90]$} \\
\hline $\begin{array}{l}\text { Albumin, serotransferrin, } \\
\text { alpha-1-antiproteinase, } \\
\text { afamin, ceruloplasmin, } \\
\text { plasminogen, and AMBP }\end{array}$ & $\uparrow$ & AD-treated rat $(n=13)$ & $\begin{array}{l}\text { LC-MS/MS validated by } \\
\text { western blot }\end{array}$ & Prognostic & [92] \\
\hline ApoA-Ib & $\uparrow$ & $\begin{array}{l}\text { Relapsing group }(n=8), \\
\text { nonrelapsing group } \\
(n=27) \text { for test and } \\
\text { relapsing group }(n=6), \\
\text { nonrelapsing group } \\
(n=34) \text { for validation }\end{array}$ & $\begin{array}{l}\text { 2DE-MALDI-TOF-MS and } \\
\text { LC-MS/MS validated by } \\
\text { western blot }\end{array}$ & Predictive & {$[124]$} \\
\hline $\begin{array}{l}\text { TRFE, A1AT, ApoA-1, } \\
\text { ANT3, A1AG1, and Robo } 4\end{array}$ & $\uparrow$ & $\begin{array}{c}\text { FSGS }(n=11), \text { IgAN } \\
(n=6), \text { and healthy control } \\
(n=8)\end{array}$ & nLC-MS/MS & Diagnostic & {$[71]$} \\
\hline $\begin{array}{l}\text { CD59, CD44, IBP7, UROM, } \\
\text { GRN, and SAP }\end{array}$ & $\downarrow$ & & & Diagnostic & {$[71]$} \\
\hline DPEP1 & - & & & Diagnostic & {$[71]$} \\
\hline Haptoglobin & $\downarrow$ & $\begin{array}{c}\text { Mild disease state }(n=5), \\
\text { advance disease state } \\
(n=5)\end{array}$ & nLC-MS/MS & Prognostic & {$[70]$} \\
\hline Ribonuclease 2 & $\uparrow$ & & & Prognostic & {$[70]$} \\
\hline APOA-1 & $\uparrow$ & $\begin{array}{c}\text { Steroid sensitive FSGS } \\
(n=6), \text { steroid resistant } \\
\text { FSGS }(n=4)\end{array}$ & nLC-MS/MS & Predictive & [69] \\
\hline MXRA8 & $\downarrow$ & & & Predictive & {$[69]$} \\
\hline $13.8 \mathrm{kDa}$ A1BG fragment & $\uparrow$ & $\begin{array}{l}\text { Steroid resistant nephrotic } \\
\text { syndrome }(n=19), \text { steroid } \\
\text { sensitive nephrotic } \\
\text { syndrome }(n=15), \text { and } \\
\text { controls }(n=10)\end{array}$ & SELDI-TOF-MS & Predictive & {$[125]$} \\
\hline
\end{tabular}

A few studies with proteomic approaches have been performed recently for identification biomarkers specially in the urine samples of FSGS patients. In several studies FSGS subjects were not the main target and were considered the control disease. Additional longitudinal studies are required to determine more valuable noninvasive biomarkers for FSGS in the context of early detection, treatment response, and prognosis.

7.1.4. Lupus Nephritis. Lupus nephritis (LN), a common consequence of systemic lupus erythematous (SLE), is associated with significant mortality and morbidity. LN is classified to six classes based on histologic presentations as well as two score indices: activity and chronicity. Currently, renal biopsy beside clinical presentations is used for diagnosis of LN. The challenging part is the treatment which differs totally based on the class and activity and chronicity indices. Therefore, careful diagnosis is critical for treatment. Moreover, current markers for LN such as proteinuria, serum creatinine level, creatinine clearance, complement levels, anti-dsDNA, and antinuclear antibodies are not sensitive or specific enough and diagnosis based on biopsy is sometimes impossible to perform invasively. Therefore, there is a need for some biomarkers which correlate with renal activity to be used for diagnosis of the disease class, early detection before renal failure, and prediction of the prognosis and response. Urinary biomarkers detected by proteomic tools are appropriate candidates to fulfill these issues.

Urinary VCAM-1, CXCL16, P-selectin, and TNFR-1 are diagnostic candidates detected and validated by ELISA [93, 94]. Urinary monocyte chemotactic protein (MCP-1) and TWEAK level have been suggested as an indicator of disease activity also using ELISA $[95,96]$. 
Detection of transferrin, ceruloplasmin, $\alpha 1$-acid-glycoprotein (AGP), lipocalin-type prostaglandin $\mathrm{D}$-synthetase (LPDGS), albumin, and albumin-related fragments in the urine of pediatric lupus nephritis patients using MALDI-TOF is one of the outstanding studies performed by Suzuki et al. [94]. Important points of this report were correlation of these candidates with disease activity and increase in level of some of them (such as transferrin, AGP, and L-PDGS) before clinical presentations of disease flare. Other candidates which were reported as predictor marker of flare were reported later by Lee et al. using SELDI-TOF [97]. They detected increased excretion of hepcidin 20 and albumin fragment (N-terminal region), four months before the flare, and decrease of excretion of hepcidin 25 at the flare time. This technique was also used by Mosley et al. for discrimination between patients with active and inactive forms of lupus nephritis [98]. The proteins with masses 3340 and 3980 were differentially excreted between these two forms which were not further identified.

A classical 2D electrophoresis followed by MALDI-TOF by Oates et al. showed a list of candidates for diagnosis of the class and chronicity of which highest sensitivity belonged to a-1 acid glycoprotein [99].

7.1.5. Membranous Nephropathy. Membranous nephropathy (MN) is categorized as one of the most common causes of primary glomerular diseases especially in adults [100]. MN is a kidney-specific autoimmune disease in which circulating autoantibodies (such as IgG4) bind to intrinsic antigen on glomerular podocytes (i.e., M-type phospholipase A2 receptor lin primary form of $\mathrm{MN}$ ), form immune complex, and deposit in subepithelial area of the basement membrane [101]. Therefore, thickening of glomerular basement membrane due to immune complex depositions is a histologic hallmark under the light microscopy [102]. As other renal diseases, the main reason for scientists' interest in discovering urinary biomarkers for $\mathrm{MN}$ is invasiveness of kidney biopsy and its potential risk of serious complications.

A classic proteomic study on urine samples collected from animal model of passive Heymann nephritis (PHN), which mimics human membranous nephropathy, using 2DPAGE and SYPRO Ruby staining followed by MALDI-TOFMS showed a panel of potential biomarkers [103]. Serial urine samples in 6 different time points after the injection with anti-FxlA were collected. Signaling pathways, glomerular trafficking, and controlling the glomerular permeability altered significantly in the disease course. Despite its good design, lack of enough number of technical replicate could be considered a weak point for their study.

Recent study on urine microvesicles obtained from idiopathic membranous nephropathy (iMN), focal segmental glomerulosclerosis (FSGS) patients, and healthy controls via iTRAQ labeling system revealed twofold increases in lysosome membrane protein-2 (LIMP-2) excretion in iMN group [104]. The pooled iTRAQ8plex samples were fractionated using strong cation exchange (SCX) and reverse phase (RP) columns and analyzed with LTQ orbitrap mass spectrometer. Glomerular expression of LIMP-2 was further investigated using immunofluorescence staining which was consistent with proteomic results.
Apart from importance of biomarkers in prompt diagnosis of this disease because of high rate of ESRD in MN patients ( 40\%) [105], identification of biomarkers predictive of responsiveness to treatment is also critical. To our knowledge, no investigation using routine proteomic tools (i.e., $2 \mathrm{DE}$ or LC coupled to mass spectrometry) is still available; however, Irazabal et al. examined the relationship between a panel of known biomarkers with responsiveness of $\mathrm{MN}$ patients to rituximab with western blot and ELISA [106]. They suggested urinary $\operatorname{IgG}(\mathrm{mg} / 24 \mathrm{~h})$ as a significant predictor for proteinuria changes at first year of therapy while fractional excretion of IgG, urinary alpha 1 microglobulin $(\mathrm{U} \alpha \mathrm{lM})(\mathrm{mg} / 24 \mathrm{~h})$, and urinary retinol binding protein (URBP) $(\mu \mathrm{g} / 24 \mathrm{~h})$ were predictor of the response at 12 months but not at 24 months.

Applying high-throughput proteomic tools in identification of the predictive biomarkers for $\mathrm{MN}$ is a promising approach which needs more effort. Some of the studies on urine proteins aiming at biomarker discovery are tabulated in Table 4.

7.1.6. Acute Kidney Injury. Acute kidney injury (AKI) is a complicated condition encompassing wide range of clinical manifestations (e.g., elevated serum creatinine and anuric renal failure) [107]. This disorder has high rate of mortality and morbidity which mostly affected critically ill patients (e.g., patients admitted to ICU) and associated with a sudden fail in renal function [108]. The markers that are currently used in clinic such as serum creatinine and decline in GFR are detected late after kidney injury. Therefore, lack of early markers leading to delay in initiating effective therapy, high risk of mortality, and high risk of ESRD explain the urgent need for AKI biomarkers that could be detected early and noninvasively. Furthermore, identification biomarkers may aid to understanding the mechanism underneath this enigmatic condition. Numbers of studies have been performed using urine proteomics that are reviewed as follows (Table 5).

Nguyen et al. performed a proteomic study on urine samples of sixty patients undergoing cardiopulmonary bypass $(\mathrm{CPB})$ and investigated acute renal injury in this cohort [109]. Urine protein profile of these patients obtained by SELDI-TOF-MS and biomarkers with $\mathrm{m} / z$ of $28.5,43$, and $66 \mathrm{kDa}$ were suggested for prediction of $\mathrm{AKI}$ at $2 \mathrm{~h}$ following CPB with sensitivity and specificity of $100 \%$. This study had promising results and highlighted the potential application of SELDI-TOF in screening patients with AKI risk. Further investigation by this group with proteomic approaches revealed aprotinin as a predictor of AKI, $2 \mathrm{~h}$ after initiation of $\mathrm{CPB}$ with sensitivity of $92 \%$ and specificity of $96 \%$ [110]. Metzger et al. performed CE-MS analysis to identify peptides predictive of AKI [111]. They suggested 20 urinary polypeptides specific for AKI and validated them in two independent, blinded ICU and cross-sectional HSCT patient cohorts. In addition, their suggested markers could detect AKI accurately 5 days before the rise of serum creatinine. The data showed overrepresentation of peptides of albumin, $\alpha-1-$ antitrypsin, and $\beta$-2-microglobulin and underrepresentation of fibrinogen $\alpha$ and collagens $1 \alpha(\mathrm{I})$ and $1 \alpha$ (III) fragments with accuracy of $91 \%$. 
TABLE 4: Biomarker candidates for MN discovered by urine proteome analysis.

\begin{tabular}{|c|c|c|c|c|c|}
\hline Protein biomarkers & Up/downregulation & Cohort & Technique & $\begin{array}{c}\text { Type of } \\
\text { biomarker }\end{array}$ & Reference \\
\hline VEGF & $\downarrow$ & $\begin{array}{c}\mathrm{MN}(n=30), \text { minimal change } \\
\text { disease }(\mathrm{MCD})(n=8), \text { FSGS } \\
\quad(n=10), \text { necrotizing } \\
\text { glomerulonephritis }(n=8), \mathrm{DN} \\
(n=12), \text { and healthy control } \\
\quad(n=33)\end{array}$ & ELISA & Diagnostic & [126] \\
\hline$\beta 2 \mathrm{~m}$ & $\uparrow$ & $\mathrm{iMN}(n=57)$ & ELISA & $\begin{array}{l}\text { Prognostic- } \\
\text { predictive }\end{array}$ & [127] \\
\hline Nephrin & - & $\begin{array}{l}\text { Passive Heymann nephritis } \\
(n=16), \text { normal rat }(n=5)\end{array}$ & Western blot & $\begin{array}{l}\text { Qualitative } \\
\text { diagnostic }\end{array}$ & {$[128]$} \\
\hline LIMP-2 & $\uparrow$ & $\begin{array}{l}\text { iMN }(n=5), \text { FSGS }(n=5), \text { and } \\
\text { healthy control }(n=3)\end{array}$ & $\begin{array}{c}\text { iTRAQ and verification } \\
\text { with immunofluorescence } \\
\text { of glomeruli }\end{array}$ & Diagnostic & {$[104]$} \\
\hline$\alpha 1 \mathrm{M}, \mathrm{URBP}$ & - & $\begin{array}{c}\text { Complete remission (CR) } \\
(n=1), \text { partial remission (PR) } \\
(n=9), \text { limited response (LR) } \\
(n=5), \text { and nonresponders (NR) } \\
(n=4)\end{array}$ & Nephelometry & Predictive & [106] \\
\hline
\end{tabular}

A comprehensive study in terms of study design was performed by Aregger et al. on patients undergoing elective cardiopulmonary bypass [112]. They analyzed protein profile in spot urine samples from thirty-six patients before and after CPB and investigated AKI (according to RIFLE criteria) using 2D-DIGE and MALDI-TOF-MS. Regulated proteins in comparison between patients before and after CPB were inflammation-associated or tubular dysfunction-associated proteins while modified urinary albumin, zinc-alpha-2glycoprotein (ZAG), and a fragment of adrenomedullinbinding protein were associated with AKI. An independent cohort of 23 patients with and 45 patients without acute kidney injury was further examined for ZAG (as it was nonmodified and nonfragmented) using western blot and ELISA. The positive points of their study were validation in an independent cohort by two methods (WB and ELISA) and definition of comprehensive exclusion criteria including great amount of proteinuria and microhematuria, CKD patients with low GFR, use of radiocontrast media or nonsteroid antiinflammatory drugs (NSAIDs), and need for urgent surgery.

Further investigation of urinary biomarkers was performed later, on the larger cohort using similar method by this research group. Sixty-four critically ill patients of whom 52 had AKI were analyzed by 2D-DIGE for separation followed by LC-ESI-MS/MS for identification of differential spots [113]. In this study, $\alpha-1$ microglobulin, $\alpha$ 1 antitrypsin, apolipoprotein $\mathrm{D}$, calreticulin, cathepsin $\mathrm{D}$, CD59, insulin-like growth factor-binding protein 7 (IGFBP7 ), and neutrophil gelatinase-associated lipocalin (NGAL) were suggested as candidate markers. IGFBP-7 and NGAL were selected for further validation using ELISA in an independent verification group of 28 patients with and 12 control patients without AKI. IGFBP-7 had better accuracy for prediction of renal outcome in their cohort.

In the most recent study, Bell et al. have investigated the association of nonrenal factors with elevated biomarker levels in AKI using ELISA [114]. They reported NGAL and cystatin C, two famous biomarkers of AKI, as well as urinary [TIMP2].[IGFBP7] as poor predictors which could not predict AKI within 12 to 48 hours and might be affected by factors other than AKI. This finding indicates the need for more study of AKI predictive biomarkers despite large number of studies performed so far and the need for more practical and precise study design.

\section{Specific Urinary Proteome Database}

Identification and characterization of candidate biomarkers which were carefully extracted from bunch of complex and confusing data using appropriate statistical methods are a critical step in a typical study for biomarker discovery. Identification of the most robust urinary protein markers is enhanced by means of databases specific for urine and kidney proteins.

Currently there are a few available databases specific for human urine proteome. A number of urine databases are based on identified proteins derived from tryptic peptides of which MAPU [115] and Sys-BodyFluid [116] are more stated. The other useful urine specific databases are tabulated in Table 6.

Max Planck Institute has provided a proteome database entitled MAPU which consists of different sources such as tear, urine, seminal fluid, and tissue from Homo sapiens and Mus musculus [115]. In the urine part MAPU contains information about 1543 proteins which were separated and fractionated using one-dimensional SDS-PAGE and reverse phase HPLC and analyzed with the LTQ-FT and LTQOrbitrap at p.p.m. accuracy after both in-gel and in-solution digestion. It worth to note that approximately half of these deposited proteins are membrane proteins according to gene ontology (GO) analysis. 
TABLE 5: Urinary candidate biomarkers for AKI.

\begin{tabular}{|c|c|c|c|c|c|}
\hline Protein biomarkers & Up/downregulation & Cohort & Technique & Type of biomarker & Reference \\
\hline IL-18 & $\uparrow$ & $\begin{array}{l}\text { AKI after CBP }(n=20), \\
\text { controls }(n=35)\end{array}$ & ELISA & Predictive & [129] \\
\hline KIM-1, NAG, and NGAL & $\uparrow$ & $\begin{array}{c}\text { AKI }(n=36), \text { early AKI } \\
(n=16), \text { late AKI }(n=20) \\
\text { and non-AKI }(n=54)\end{array}$ & ELISA & Predictive & {$[130]$} \\
\hline Aprotinin & $\uparrow$ & $\begin{array}{c}106 \text { pediatric patients } \\
\text { undergoing CPB }\end{array}$ & SELDI-TOF-MS & Predictive & {$[110]$} \\
\hline NGAL & $\uparrow$ & $\begin{array}{l}71 \text { children undergoing } \\
\text { cardiopulmonary bypass }\end{array}$ & $\begin{array}{l}\text { Western blot and } \\
\text { ELISA }\end{array}$ & Predictive & {$[131]$} \\
\hline KIM-1 & $\uparrow$ & $\begin{array}{c}\text { Cisplatin-induced } \\
\text { nephrotoxic rats }(n=4)\end{array}$ & ELISA & Predictive & {$[132]$} \\
\hline $\begin{array}{l}\text { Albumin, } \alpha \text {-1-antitrypsin, } \\
\text { and } \beta \text {-2-microglobulin }\end{array}$ & $\uparrow$ & $\begin{array}{l}\text { AKI }(n=16) \text { and non-AKI } \\
(n=14) \text { from ICU patients } \\
\text { as training set, AKI }(n=9) \\
\text { and non-AKI }(n=11) \text { from } \\
\text { ICU patients, and AKI } \\
(n=13) \text { and non-AKI } \\
(n=19) \text { from HSCT } \\
\text { patients as validation set }\end{array}$ & CE-MS & Diagnostic & [111] \\
\hline $\begin{array}{l}\text { Fibrinogen } \alpha \text { and collagens } \\
1 \alpha(\mathrm{I}) \text { and } 1 \alpha(\mathrm{III})\end{array}$ & $\downarrow$ & & CE-MS & Diagnostic & {$[111]$} \\
\hline $\begin{array}{l}\text { Zinc-alpha-2-glycoprotein } \\
\text { and a fragment of } \\
\text { adrenomedullin-binding } \\
\text { protein }\end{array}$ & $\downarrow$ & $\begin{array}{l}\text { Discovery cohort: AKI } \\
(n=6) \text { and non-AKI } \\
(n=6) ; \text { validation cohort: } \\
\text { AKI }(n=23) \text { and non-AKI } \\
(n=45)\end{array}$ & $\begin{array}{c}\text { 2D-DIGE and } \\
\text { MALDI-TOF-MS and } \\
\text { validation by ELISA } \\
\text { and western blot }\end{array}$ & Predictive & {$[112]$} \\
\hline IGFBP-7 and NGAL & $\uparrow$ & $\begin{array}{c}\text { LNR }(n=26), \operatorname{ER}(n=26), \\
\text { and control }(n=12)\end{array}$ & $\begin{array}{c}\text { 2D-DIGE and } \\
\text { validation by ELISA }\end{array}$ & Diagnostic/prognostic & {$[113]$} \\
\hline Netrin-1 & $\uparrow$ & $\begin{array}{c}\text { AKI }(n=26), \text { non-AKI } \\
(n=34)\end{array}$ & ELISA & Predictive & {$[133]$} \\
\hline $\begin{array}{l}\alpha 1 \text {-microglobulin, } \alpha 1 \text {-acid } \\
\text { glycoprotein, and albumin }\end{array}$ & $\uparrow$ & $\begin{array}{c}\text { Discovery cohort: AKI } \\
(n=15) \text { and control } \\
(n=15) \text {; validation cohort: } \\
\text { AKI }(n=135) \text { and control } \\
(n=230)\end{array}$ & $\begin{array}{l}\text { SELDI-TOF-MS and } \\
\text { validation by } \\
\text { nephelometry }\end{array}$ & Diagnostic/prognostic & {$[134]$} \\
\hline Hsp72 & $\uparrow$ & $\begin{array}{c}\text { AKI }(n=17), \text { control } \\
(n=20)\end{array}$ & ELISA & Predictive & {$[135]$} \\
\hline
\end{tabular}

TABLE 6: Databases for proteomics of urine.

\begin{tabular}{lcc}
\hline Database & Organization/company & Address \\
\hline Sys-BodyFluid & Shanghai Institutes for Biological Science & http://www.biosino.org/bodyfluid/ \\
\hline MAPU & $\begin{array}{c}\text { Max Planck Institute for Biochemistry } \\
\text { (Germany) }\end{array}$ & http://www.mapuproteome.com/ \\
\hline HKUPP & Human Proteome Organization & http://www.hkupp.org/ \\
\hline $\begin{array}{l}\text { Urinary Exosome } \\
\text { Protein Database }\end{array}$ & NHLBI Laboratory of Kidney and Electrolyte \\
Mrinary Protein & Chinese Academy of Medical Sciences and \\
Biomarker Database & Peking Union Medical College & http://dir.nhlbi.nih.gov/papers/lkem/exosome/index.htm \\
\hline $\begin{array}{l}\text { Mosaique } \\
\text { The Mosaiques Diagnostics \& Therapeutics } \\
\text { AG (Germany) }\end{array}$ & http://122.70.220.102/biomarker/ \\
\hline
\end{tabular}


Sys-BodyFluid is a comprehensive proteome database which is composed of 11 body fluid proteomes including urine [116]. The data deposited in this database come from 50 peerreview publications of different laboratories across the world. Information and annotation of proteins are description, gene ontology, domain information, protein sequence, and involved pathway.

Mosaiques diagnostics database is known as peptidome urinary database including 13027 urine samples taken from both diseased and healthy subjects that is obtained by analytical platform CE-MS [117]. Another part of the urinary Mosaiques database is biomarker sequence information which was obtained for 953 peptides that are deriving from 116 different proteins [115, 117].

Human urinary proteomic fingerprint database (UPdb) was established in 2013, using urine samples from 200 individuals analyzed by SELDI-MS on several chip surfaces (SEND, HP50, NP20, Q10, CM10, and IMAC30). The database lists 2490 unique peaks/ion species from 1172 nonredundant SELDI analyses as well as 1384 included peaks from external studies using CE-MS, MALDI, and CE-MALDI hybrids. The database provides information relating to the MS environment, subfractionation methods, chromatography setups, studied diseases, identified biomarker, statistical information, and identified proteins.

\section{Conclusion}

Urine is a valuable source of molecules which is capable of being diagnostic markers specially for renal diseases. The strength of urine in comparison to plasma and tissue samples is the noninvasive collection procedure and less complex protein content. The complications in biopsy based diagnosis (i.e., invasiveness, dependence of diagnosis on pathologist tact and observation, limitations due to infection, hypertension, and kidney size) make urinary biomarkers a safe reliable complement alternative way for diagnosis beside traditional biopsy. In addition, lack of limitation in amount of specimen at the time of collection and relatively stable content of peptides and proteins because of complete proteolytic process by endogenous proteases during the storage in the bladder make urine an ideal specimen for biomarker researches. As urinary proteins are mainly originating from kidney tissue ( $70 \%$ ) (remaining 30\% derived from plasma), therefore urine is the most appropriate sample for biomarker discovery in renal disease, urogenital track, and vascular system.

However, molecular biomarkers have not become practical in clinics yet, and extensive attempts have been devoted to validate these molecular markers. Proteomic techniques beside advanced statistical analysis and bioinformatics knowledge are versatile tools in urinary biomarker discovery. It is expected that advances in analytical tools and software programs as well as accurate study design in the near future will improve sensitivity and specificity of available biomarkers.

\section{Abbreviations}

IgA: Immunoglobulin A

2D: Two-dimensional

2DE-MS: Two-dimensional gel electrophoresis

followed by mass spectrometry

LC-MS: $\quad$ Liquid chromatography coupled to mass spectrometry

CE-MS: Capillary electrophoresis coupled to mass spectrometry

2D-DIGE: Two-dimensional difference gel electrophoresis

LC: $\quad$ Liquid chromatography

SCX: $\quad$ Strong cation exchange column

FTICR: $\quad$ Fourier transform ion cyclotron resonance

SELDI-TOF: Surface-enhanced laser desorption/ionization time of flight

DN: Diabetic nephropathy

MA: Microalbuminuria

THP: Tamm-Horse fall urinary glycoprotein

ZA2G: $\quad$ Zinc- $\alpha$-2 glycoprotein

IgAN: $\quad \operatorname{IgA}$ nephropathy

IGFBP7: Insulin-like growth factor-binding protein 7

TEC: Tubular epithelial cell

LN: $\quad$ Lupus nephritis

SLE: $\quad$ Systemic lupus erythematous

MCP-1: Monocyte chemotactic protein

AGP: $\quad \alpha 1$-acid-glycoprotein

LPDGS: Lipocalin-type prostaglandin

D-synthetase

CVD: $\quad$ Cardiovascular disease

CAD: Coronary artery disease

HF: $\quad$ Heart failure

NCD: $\quad$ Noncardiac dyspnea patients

CHF: $\quad$ Chronic heart failure

AHF: Acute heart failure

IGFBP2: Insulin-like growth factor binding protein 2

NF- $\kappa \mathrm{B}: \quad$ Nuclear factor $\kappa \mathrm{B}$

IBS: Irritable bowel syndrome

GI: Gastrointestinal

TFF3: $\quad$ Trefoil Factor 3

uGI: Upper gastrointestinal

GA: Genetic algorithm

FDP: $\quad$ Fibrinogen degradation products

GO: Gene ontology

UPdb: Urinary proteomic fingerprint database

LNR: Late/nonrecovery

ER: $\quad$ Early recovery

AKI: $\quad$ Acute kidney injury

MN: $\quad$ Membranous nephropathy

iMN: $\quad$ Idiopathic membranous nephropathy

PHN: $\quad$ Passive Heymann nephritis

FSGS: $\quad$ Focal segmental glomerulosclerosis

iTRAQ: $\quad$ Isobaric tags for relative and absolute quantification

LIMP-2: $\quad$ Lysosome membrane protein-2 
RP: $\quad$ Reverse phase

U $\alpha 1 \mathrm{M}: \quad$ Urinary alpha 1 microglobulin

URBP: Urinary retinol binding protein

ICU: Intensive care unit

CPB: $\quad$ Cardiopulmonary bypass

WB: Western blot

CKD: Chronic kidney disease

NSAIDs: Nonsteroid anti-inflammatory drugs

IGFBP-7: Insulin-like growth factor-binding protein 7

NGAL: Neutrophil gelatinase-associated lipocalin

ADR: Adriamycin

MARS: Multiple affinity removal system

FSGS: Focal segmental glomerulosclerosis.

\section{Disclosure}

The authors namely A. Jafari, R. Moradpoor, E. Ghasemi, and E. Khalkhal are Ph.D. students in applied proteomics. S. Kalantari is assistant professor in chronic kidney disease research center at Shahid Beheshti University of Medical Sciences in Tehran.

\section{Conflict of Interests}

There is no competing interests regarding the publication of this paper.

\section{Authors' Contribution}

R. Moradpoor, A. Jafari, E. Ghasemi, and E. Khalkhal contributed equally to writing this paper and researching the data. S. Kalantari contributed to conceive, design, writing, and edition of the paper. All authors read and approved the final paper.

\section{Acknowledgment}

The authors are grateful to Chronic Kidney Disease Research Center for help and support.

\section{References}

[1] J. Adachi, C. Kumar, Y. Zhang, J. V. Olsen, and M. Mann, “The human urinary proteome contains more than 1500 proteins, including a large proportion of membrane proteins," Genome Biology, vol. 7, article R80, 2006.

[2] H. Husi, N. Stephens, A. Cronshaw et al., "Proteomic analysis of urinary upper gastrointestinal cancer markers," PROTEOMICS-Clinical Applications, vol. 5, no. 5-6, pp. 289299, 2011.

[3] V. C. Wasinger, M. Zeng, and Y. Yau, "Current status and advances in quantitative proteomic mass spectrometry," International Journal of Proteomics, vol. 2013, Article ID 180605, 12 pages, 2013.

[4] D. M. Good, V. Thongboonkerd, J. Novak et al., "Body fluid proteomics for biomarker discovery: lessons from the past hold the key to success in the future," Journal of Proteome Research, vol. 6, no. 12, pp. 4549-4555, 2007.
[5] S. Cui, P. J. Verroust, S. K. Moestrup, and E. I. Christensen, "Megalin/gp330 mediates uptake of albumin in renal proximal tubule," American Journal of Physiology-Renal Fluid and Electrolyte Physiology, vol. 271, no. 4, pp. F900-F907, 1996.

[6] T. Pisitkun, R.-F. Shen, and M. A. Knepper, "Identification and proteomic profiling of exosomes in human urine," Proceedings of the National Academy of Sciences of the United States of America, vol. 101, no. 36, pp. 13368-13373, 2004.

[7] A. Castagna, D. Cecconi, L. Sennels et al., "Exploring the hidden human urinary proteome via ligand library beads," Journal of Proteome Research, vol. 4, no. 6, pp. 1917-1930, 2005.

[8] R. Pieper, C. L. Gatlin, A. M. McGrath et al., "Characterization of the human urinary proteome: a method for high-resolution display of urinary proteins on two-dimensional electrophoresis gels with a yield of nearly 1400 distinct protein spots," Proteomics, vol. 4, no. 4, pp. 1159-1174, 2004.

[9] W. Sun, F. Li, S. Wu et al., "Human urine proteome analysis by three separation approaches," Proteomics, vol. 5, no. 18, pp. 4994-5001, 2005.

[10] L. Wang, F. Li, W. Sun et al., "Concanavalin A-captured glycoproteins in healthy human urine," Molecular and Cellular Proteomics, vol. 5, no. 3, pp. 560-562, 2006.

[11] M. Ożgo, W. F. Skrzypczak, A. Herosimczyk, and A. Mazur, "Proteomika a fizjologia i patofizjologia nerek," MedWet, vol. 63, pp. 1146-1150, 2007.

[12] B. Haraldsson and J. Sörensson, "Why do we not all have proteinuria? An update of our current understanding of the glomerular barrier," News in Physiological Sciences, vol. 19, no. 1, pp. 7-10, 2004.

[13] A. B. Maunsbach, "Absorption of I125-labeled homologous albumin by rat kidney proximal tubule cells. A study of microperfused single proximal tubules by electron microscopic autoradiography and histochemistry, 1966," Journal of the American Society of Nephrology, vol. 8, no. 2, pp. 323-351, 1997.

[14] M. J. Burne, T. M. Osicka, and W. D. Comper, "Fractional clearance of high molecular weight proteins in conscious rats using a continuous infusion method," Kidney International, vol. 55, no. 1, pp. 261-270, 1999.

[15] V. Batuman, P. J. Verroust, G. L. Navar et al., "Myeloma light chains are ligands for cubilin (gp280)," American Journal of Physiology-Renal Physiology, vol. 275, no. 2, pp. F246-F254, 1998.

[16] E. I. Christensen and J. Gburek, "Protein reabsorption in renal proximal tubule-function and dysfunction in kidney pathophysiology," Pediatric Nephrology, vol. 19, no. 7, pp. 714721, 2004.

[17] M. Afkarian, M. Bhasin, S. T. Dillon et al., "Optimizing a proteomics platform for urine biomarker discovery," Molecular and Cellular Proteomics, vol. 9, no. 10, pp. 2195-2204, 2010.

[18] J. Peng and S. P. Gygi, "Proteomics: the move to mixtures," Journal of Mass Spectrometry, vol. 36, no. 10, pp. 1083-1091, 2001.

[19] V. Thongboonkerd, "Proteomics in nephrology: current status and future directions," American Journal of Nephrology, vol. 24, no. 3, pp. 360-378, 2004.

[20] A. Marimuthu, R. N. O’Meally, R. Chaerkady et al., "A comprehensive map of the human urinary proteome," Journal of Proteome Research, vol. 10, no. 6, pp. 2734-2743, 2011.

[21] Q.-R. Li, K.-X. Fan, R.-X. Li et al., "A comprehensive and non-prefractionation on the protein level approach for the human urinary proteome: touching phosphorylation in urine," Rapid Communications in Mass Spectrometry, vol. 24, no. 6, pp. 823-832, 2010. 
[22] P. A. Gonzales, T. Pisitkun, J. D. Hoffert et al., "Large-scale proteomics and phosphoproteomics of urinary exosomes," Journal of the American Society of Nephrology, vol. 20, no. 2, pp. 363-379, 2009.

[23] A. Khan and N. H. Packer, "Simple urinary sample preparation for proteomic analysis," Journal of Proteome Research, vol. 5, no. 10, pp. 2824-2838, 2006.

[24] V. Thongboonkerd, S. Chutipongtanate, and R. Kanlaya, "Systematic evaluation of sample preparation methods for gel-based human urinary proteomics: quantity, quality, and variability," Journal of Proteome Research, vol. 5, no. 1, pp. 183-191, 2006.

[25] G. Gopalan, V. S. Rao, and V. V. Kakar, "An overview of urinary proteomics applications in human diseases," International Journal of High Throughput Screening, vol. 1, pp. 183-192, 2010.

[26] H.-Y. Tang, L. A. Beer, and D. W. Speicher, "In-depth analysis of a plasma or serum proteome using a $4 \mathrm{D}$ protein profiling method," Methods in Molecular Biology, vol. 728, pp. 47-67, 2011.

[27] N. S. Vasudev, R. E. Ferguson, D. A. Cairns, A. J. Stanley, P. J. Selby, and R. E. Banks, "Serum biomarker discovery in renal cancer using 2-DE and prefractionation by immunodepletion and isoelectric focusing; increasing coverage or more of the same?" Proteomics, vol. 8, no. 23-24, pp. 5074-5085, 2008.

[28] C.-L. Chen, T.-S. Lin, C.-H. Tsai et al., "Identification of potential bladder cancer markers in urine by abundant-protein depletion coupled with quantitative proteomics," Journal of Proteomics, vol. 85, pp. 28-43, 2013.

[29] S. Filip, K. Vougas, J. Zoidakis et al., "Comparison of depletion strategies for the enrichment of low-abundance proteins in urine," PLoS ONE, vol. 10, no. 7, Article ID e0133773, 2015.

[30] C.-M. Lu, Y.-J. Wu, C.-C. Chen et al., "Identification of lowabundance proteins via fractionation of the urine proteome with weak anion exchange chromatography," Proteome Science, vol. 9, article 17, 2011.

[31] S. A. Beausoleil, M. Jedrychowski, D. Schwartz et al., "Largescale characterization of HeLa cell nuclear phosphoproteins," Proceedings of the National Academy of Sciences of the United States of America, vol. 101, no. 33, pp. 12130-12135, 2004.

[32] V. Thongboonkerd, T. Semangoen, and S. Chutipongtanate, "Enrichment of the basic/cationic urinary proteome using ion exchange chromatography and batch adsorption," Journal of Proteome Research, vol. 6, no. 3, pp. 1209-1214, 2007.

[33] M. M. Kushnir, P. Mrozinski, A. L. Rockwood, and D. K. Crockett, "A depletion strategy for improved detection of human proteins from urine," Journal of Biomolecular Techniques, vol. 20, no. 2, pp. 101-108, 2009.

[34] V. Thongboonkerd, "Current status of renal and urinary proteomics: ready for routine clinical application," Nephrology Dialysis Transplantation, vol. 25, no. 1, pp. 11-16, 2010.

[35] S. Decramer, A. G. de Peredo, B. Breuil et al., "Urine in clinical proteomics," Molecular and Cellular Proteomics, vol. 7, no. 10, pp. 1850-1862, 2008.

[36] J. Jia and L. Zhang, "Advance in proteomics research and application," Journal of Animal and Veterinary Advances, vol. 11, no. 20, pp. 3812-3817, 2012.

[37] H. Dihazi, "The urinary proteomics: a tool to discover new and potent biomarkers for kidney damage," Journal of the International Federation of Clinical Chemistry and Laboratory Medicine, vol. 20, no. 1, pp. 82-91, 2009.

[38] J. M. González-Buitrago, L. Ferreira, and I. Lorenzo, "Urinary proteomics," Clinica Chimica Acta, vol. 375, no. 1-2, pp. 49-56, 2007.
[39] M. M. Camacho-Carvcajal, B. Wollscheid, R. Aebersold, V. Steimle, and W. W. A. Schamel, "Two-dimensional Blue Native/SDS gel electrophoresiss of multi-protein complexes from whole cellular lysates: a proteomics approach," Molecular and Cellular Proteomics, vol. 3, no. 2, pp. 176-182, 2004.

[40] I. Neverova and J. E. Van Eyk, "Role of chromatographic techniques in proteomic analysis," Journal of Chromatography B: Analytical Technologies in the Biomedical and Life Sciences, vol. 815, no. 1-2, pp. 51-63, 2005.

[41] T. Niwa, "Biomarker discovery for kidney diseases by mass spectrometry," Journal of Chromatography B, vol. 870, no. 2, pp. 148-153, 2008.

[42] M. G. Janech, J. R. Raymond, and J. M. Arthur, "Proteomics in renal research," The American Journal of Physiology-Renal Physiology, vol. 292, no. 2, pp. F501-F512, 2007.

[43] P. Rossing, "The changing epidemiology of diabetic microangiopathy in type 1 diabetes," Diabetologia, vol. 48, no. 8, pp. 1439-1444, 2005.

[44] G. Soldatos and M. E. Cooper, "Diabetic nephropathy: important pathophysiologic mechanisms," Diabetes Research and Clinical Practice, vol. 82, no. 1, pp. S75-S79, 2008.

[45] A. Soggiu, C. Piras, L. Bonizzi, H. A. Hussein, S. Pisanu, and P. Roncada, "A discovery-phase urine proteomics investigation in type 1 diabetes," Acta Diabetologica, vol. 49, no. 6, pp. 453-464, 2012.

[46] S. Kalantari, D. Rutishauser, S. Samavat et al., "Urinary prognostic biomarkers and classification of IgA nephropathy by high resolution mass spectrometry coupled with liquid chromatography," PLoS ONE, vol. 8, no. 12, Article ID e80830, 2013.

[47] B. Xin, D. Pu, S. X. Xiong, and G. H. Wang, "On-line separation and detection of peptides by capillary electrophoresis/electrospray FT-ICR-MS," Chinese Chemical Letters, vol. 14, pp. 191-194, 2003.

[48] D. Fliser, J. Novak, V. Thongboonkerd et al., "Advances in urinary proteome analysis and biomarker discovery," Journal of the American Society of Nephrology, vol. 18, no. 4, pp. 1057-1071, 2007.

[49] Z. Liu, Z. Yuan, and Q. Zhao, "SELDI-TOF-MS proteomic profiling of serum, urine, and amniotic fluid in neural tube defects," PLoS ONE, vol. 9, no. 7, Article ID e103276, 2014.

[50] J. Siwy, A. Vlahou, L. U. Zimmerli, P. Zürbig, and E. Schiffer, "Clinical proteomics: current techniques and potential applications in the elderly," Maturitas, vol. 68, no. 3, pp. 233-244, 2011.

[51] H. Mischak, E. Schiffer, P. Zürbig, M. Dakna, and J. Metzger, "Urinary proteome analysis using capillary electrophoresis coupled to mass spectrometry: a powerful tool in clinical diagnosis, prognosis and therapy evaluation," Journal of Medical Biochemistry, vol. 28, no. 4, pp. 223-234, 2009.

[52] G. A. Müller, C. A. Müller, and H. Dihazi, "Clinical proteomics-on the long way from bench to bedside?" Nephrology Dialysis Transplantation, vol. 22, no. 5, pp. 1297-1300, 2007.

[53] A. Albalat, H. Mischak, and W. Mullen, "Urine proteomics in clinical applications: technologies, principal considerations and clinical implementation," Prilozi, vol. 32, pp. 44-45, 2011.

[54] M. M. Nilsen, K.-E. Uleberg, E. A. M. Janssen, J. P. A. Baak, O. K. Andersen, and A. Hjelle, "From SELDI-TOF MS to protein identification by on-chip elution," Journal of Proteomics, vol. 74, no. 12, pp. 2995-2998, 2011.

[55] C. Ibáñez, C. Simó, V. García-Cañas, A. Cifuentes, and M. Castro-Puyana, "Metabolomics, peptidomics and proteomics applications of capillary electrophoresis-mass spectrometry in 
Foodomics: a review," Analytica Chimica Acta, vol. 802, pp. 113, 2013.

[56] H. Mischak, J. J. Coon, J. Novak, E. M. Weissinger, J. P. Schanstra, and A. F. Dominiczak, "Capillary electrophoresismass spectrometry as a powerful tool in biomarker discovery and clinical diagnosis: an update of recent developments," Mass Spectrometry Reviews, vol. 28, no. 5, pp. 703-724, 2009.

[57] J. Wu, Y.-D. Chen, and W. Gu, "Urinary proteomics as a novel tool for biomarker discovery in kidney diseases," Journal of Zhejiang University: Science B, vol. 11, no. 4, pp. 227-237, 2010.

[58] C. Simó, A. Cifuentes, and V. Kašička, "Capillary electrophoresis-mass spectrometry for peptide analysis: targetbased approaches and proteomics/ peptidomics strategies," Methods in Molecular Biology, vol. 984, pp. 139-151, 2013.

[59] S. Hu, J. A. Loo, and D. T. Wong, "Human body fluid proteome analysis," Proteomics, vol. 6, no. 23, pp. 6326-6353, 2006.

[60] P. Díez, N. Dasilva, M. González-González et al., "Data analysis strategies for protein microarrays," Microarrays, vol. 1, pp. 6483, 2012.

[61] R. Chen and M. Snyder, "Yeast proteomics and protein microarrays," Journal of Proteomics, vol. 73, no. 11, pp. 2147-2157, 2010.

[62] W. Ruige and Y. S. Fung, "Microfluidic chip-capillary electrophoresis device for the determination of urinary metabolites and proteins," Bioanalysis, vol. 7, pp. 907-922, 2015.

[63] W. P. Guo, Z. B. Rong, Y. H. Li, Y. S. Fung, G. Q. Gao, and Z. M. Cai, "Microfluidic chip capillary electrophoresis coupled with electrochemiluminescence for enantioseparation of racemic drugs using central composite design optimization," Electrophoresis, vol. 34, no. 20-21, pp. 2962-2969, 2013.

[64] C.-C. Lin, C.-C. Tseng, T.-K. Chuang, D.-S. Lee, and G.-B. Lee, "Urine analysis in microfluidic devices," Analyst, vol. 136, no. 13, pp. 2669-2688, 2011.

[65] J. R. Wiśniewski, A. Zougman, N. Nagaraj, and M. Mann, "Universal sample preparation method for proteome analysis," Nature Methods, vol. 6, no. 5, pp. 359-362, 2009.

[66] Y. Yu, M.-J. Suh, P. Sikorski, K. Kwon, K. E. Nelson, and R. Pieper, "Urine sample preparation in 96-well filter plates for quantitative clinical proteomics," Analytical Chemistry, vol. 86, no. 11, pp. 5470-5477, 2014.

[67] Y. Lyutvinskiy, H. Yang, D. Rutishauser, and R. A. Zubarev, "In silico instrumental response correction improves precision of label-free proteomics and accuracy of proteomics-based predictive models," Molecular and Cellular Proteomics, vol. 12, no. 8, pp. 2324-2331, 2013.

[68] S. Samavat, S. Kalantari, M. Nafar et al., "Diagnostic urinary proteome profile for immunoglobulin a nephropathy," Iranian Journal of Kidney Diseases, vol. 9, pp. 239-248, 2015.

[69] S. Kalantari, M. Nafar, D. Rutishauser et al., "Predictive urinary biomarkers for steroid-resistant and steroid-sensitive focal segmental glomerulosclerosis using high resolution mass spectrometry and multivariate statistical analysis," BMC Nephrology, vol. 15, no. 1, article 141, 2014.

[70] S. Kalantari, M. Nafar, S. Samavat, M. Rezaei-Tavirani, D. Rutishauser, and R. Zubarev, "Urinary prognostic biomarkers in patients with focal segmental glomerulosclerosis," NephroUrology Monthly, vol. 6, no. 2, Article ID e16806, 2014.

[71] M. Nafar, S. Kalantari, S. Samavat, M. Rezaei-Tavirani, D. Rutishuser, and R. A. Zubarev, "The novel diagnostic biomarkers for focal segmental glomerulosclerosis," International Journal of Nephrology, vol. 2014, Article ID 574261, 10 pages, 2014.
[72] J. Cox, M. Y. Hein, C. A. Luber, I. Paron, N. Nagaraj, and M. Mann, "Accurate proteome-wide label-free quantification by delayed normalization and maximal peptide ratio extraction, termed MaxLFQ," Molecular and Cellular Proteomics, vol.13, no. 9, pp. 2513-2526, 2014.

[73] K. A. Neilson, N. A. Ali, S. Muralidharan et al., "Less label, more free: approaches in label-free quantitative mass spectrometry," Proteomics, vol. 11, no. 4, pp. 535-553, 2011.

[74] S. Nahnsen, C. Bielow, K. Reinert, and O. Kohlbacher, "Tools for label-free peptide quantification," Molecular and Cellular Proteomics, vol. 12, no. 3, pp. 549-556, 2013.

[75] L. Su, R. Zhou, C. Liu et al., "Urinary proteomics analysis for sepsis biomarkers with iTRAQ labeling and two-dimensional liquid chromatography-tandem mass spectrometry," Journal of Trauma and Acute Care Surgery, vol. 74, no. 3, pp. 940-945, 2013.

[76] M. T. Davis, C. S. Spahr, M. D. McGinley et al., “Towards defining the urinary proteome using liquid chromatographytandem mass spectrometry II. Limitations of complex mixture analyses," Proteomics, vol. 1, no. 1, pp. 108-117, 2001.

[77] H. Mischak, J. P. A. Ioannidis, A. Argiles et al., "Implementation of proteomic biomarkers: making it work," European Journal of Clinical Investigation, vol. 42, no. 9, pp. 1027-1036, 2012.

[78] B. Jim, M. Ghanta, A. Qipo et al., "Dysregulated nephrin in diabetic nephropathy of type 2 diabetes: a cross sectional study," PLoS ONE, vol. 7, no. 5, Article ID e36041, 2012.

[79] P. Zürbig, G. Jerums, P. Hovind et al., "Urinary proteomics for early diagnosis in diabetic nephropathy," Diabetes, vol. 61, no. 12, pp. 3304-3313, 2012.

[80] A. Lewandowicz, M. Bakun, R. Kohutnicki et al., "Changes in urine proteome accompanying diabetic nephropathy progression," Polskie Archiwum Medycyny Wewnetrznej, vol. 125, pp. 27-38, 2015.

[81] J. Barratt and J. Feehally, "IgA nephropathy," Journal of the American Society of Nephrology, vol. 16, no. 7, pp. 2088-2097, 2005.

[82] B. A. Julian, S. Wittke, M. Haubitz et al., "Urinary biomarkers of IgA nephropathy and other IgA-associated renal diseases," World Journal of Urology, vol. 25, no. 5, pp. 467-476, 2007.

[83] M. T. Rocchetti, M. Papale, A. M. d'Apollo et al., "Association of urinary laminin G-like 3 and free $\mathrm{K}$ light chains with disease activity and histological injury in IgA nephropathy," Clinical Journal of the American Society of Nephrology, vol. 8, no. 7, pp. 1115-1125, 2013.

[84] B. A. Julian, S. Wittke, J. Novak et al., "Electrophoretic methods for analysis of urinary polypeptides in $\lg \mathrm{A}$-associated renal diseases," Electrophoresis, vol. 28, no. 23, pp. 4469-4483, 2007.

[85] S. Zhao, R. Li, X. Cai et al., "The application of SILAC mouse in human body fluid proteomics analysis reveals protein patterns associated with IgA nephropathy," Evidence-Based Complementary and Alternative Medicine, vol. 2013, Article ID 275390, 10 pages, 2013.

[86] K. Mucha, M. Bakun, R. Jaźwiec et al., "Complement components, proteolysis-related, and cell communication-related proteins detected in urine proteomics are associated with IgA nephropathy," Polskie Archiwum Medycyny Wewnetrznej, vol. 124, no. 7-8, pp. 380-386, 2014.

[87] V. D. D’Agati, F. J. Kaskel, and R. J. Falk, "Focal segmental glomerulosclerosis," The New England Journal of Medicine, vol. 365, no. 25, pp. 2398-2411, 2011. 
[88] B. Bose and D. Cattran, "Glomerular diseases: FSGS," Clinical Journal of the American Society of Nephrology, vol. 9, no. 3, pp. 626-632, 2014.

[89] C. Kitiyakara, J. B. Kopp, and P. Eggers, "Trends in the epidemiology of focal segmental glomerulosclerosis," Seminars in Nephrology, vol. 23, no. 2, pp. 172-182, 2003.

[90] H.-A. Shui, T.-H. Huang, S.-M. Ka, P.-H. Chen, Y.-F. Lin, and A. Chen, "Urinary proteome and potential biomarkers associated with serial pathogenesis steps of focal segmental glomerulosclerosis," Nephrology Dialysis Transplantation, vol. 23, no. 1, pp. 176-185, 2008.

[91] R. P. Woroniecki, T. N. Orlova, N. Mendelev et al., "Urinary proteome of steroid-sensitive and steroid-resistant idiopathic nephrotic syndrome of childhood," American Journal of Nephrology, vol. 26, no. 3, pp. 258-267, 2006.

[92] M. Zhao, M. Li, X. Li, C. Shao, J. Yin, and Y. Gao, "Dynamic changes of urinary proteins in a focal segmental glomerulosclerosis rat model," Proteome Science, vol. 12, article 42, 2014.

[93] T. Wu, C. Xie, H. W. Wang et al., "Elevated urinary VCAM-1, P-selectin, soluble TNF receptor-1, and CXC chemokine ligand 16 in multiple murine lupus strains and human lupus nephritis," Journal of Immunology, vol. 179, no. 10, pp. 7166-7175, 2007.

[94] M. Suzuki, K. Wiers, E. B. Brooks et al., "Initial validation of a novel protein biomarker panel for active pediatric lupus nephritis," Pediatric Research, vol. 65, no. 5, pp. 530-536, 2009.

[95] R. F. Rosa, K. Takei, N. C. Araújo, S. M. A. Loduca, J. C. M. Szajubok, and W. H. Chahade, "Monocyte chemoattractant-1 as a urinary biomarker for the diagnosis of activity of lupus nephritis in Brazilian patients," The Journal of Rheumatology, vol. 39, no. 10, pp. 1948-1954, 2012.

[96] Z. Xuejing, T. Jiazhen, L. Jun, X. Xiangqing, Y. Shuguang, and L. Fuyou, "Urinary TWEAK level as a marker of lupus nephritis activity in 46 cases," Journal of Biomedicine and Biotechnology, vol. 2012, Article ID 359647, 7 pages, 2012.

[97] P. Lee, H. Peng, T. Gelbart, L. Wang, and E. Beutler, "Regulation of hepcidin transcription by interleukin-1 and interleukin-6," Proceedings of the National Academy of Sciences of the United States of America, vol. 102, no. 6, pp. 1906-1910, 2005.

[98] K. Mosley, F. W. K. Tam, R. J. Edwards, J. Crozier, C. D. Pusey, and L. Lightstone, "Urinary proteomic profiles distinguish between active and inactive lupus nephritis," Rheumatology, vol. 45, no. 12, pp. 1497-1504, 2006.

[99] J. C. Oates, S. Varghese, A. M. Bland et al., "Prediction of urinary protein markers in lupus nephritis," Kidney International, vol. 68, no. 6, pp. 2588-2592, 2005.

[100] W. Sui, R. Zhang, J. Chen et al., "Comparative proteomic analysis of membranous nephropathy biopsy tissues using quantitative proteomics," Experimental and Therapeutic Medicine, vol. 9, no. 3, pp. 805-810, 2015.

[101] L. H. Beck Jr. and D. J. Salant, "Membranous nephropathy: forms models to man," Journal of Clinical Investigation, vol. 124, no. 6, pp. 2307-2314, 2014.

[102] L. H. Beck Jr. and D. J. Salant, "Membranous nephropathy: recent travels and new roads ahead," Kidney International, vol. 77, no. 9, pp. 765-770, 2010.

[103] H. H.-Y. Ngai, W.-H. Sit, P.-P. Jiang, R.-J. Xu, J. M.-F. Wan, and V. Thongboonkerd, "Serial changes in urinary proteome profile of membranous nephropathy: implications for pathophysiology and biomarker discovery," Journal of Proteome Research, vol. 5, no. 11, pp. 3038-3047, 2006.
[104] I. M. Rood, M. L. Merchant, D. W. Wilkey et al., "Increased expression of lysosome membrane protein 2 in glomeruli of patients with idiopathic membranous nephropathy," Proteomics, vol. 15, no. 21, pp. 3722-3730, 2015.

[105] P. Ruggenenti, C. Chiurchiu, V. Brusegan et al., "Rituximab in idiopathic membranous nephropathy: a one-year prospective study," Journal of the American Society of Nephrology, vol. 14, no. 7, pp. 1851-1857, 2003.

[106] M. V. Irazabal, A. Eirin, J. Lieske et al., "Low-and highmolecular-weight urinary proteins as predictors of response to rituximab in patients with membranous nephropathy: a prospective study," Nephrology Dialysis Transplantation, vol. 28, no. 1, pp. 137-146, 2013.

[107] R. L. Mehta, J. A. Kellum, S. V. Shah et al., "Acute kidney injury network: report of an initiative to improve outcomes in acute kidney injury," Critical Care, vol. 11, article R31, 2007.

[108] S. Herget-Rosenthal, J. Metzger, A. Albalat, V. Bitsika, and H. Mischak, "Proteomic biomarkers for the early detection of acute kidney injury," Prilozi, vol. 33, pp. 27-48, 2012.

[109] M. T. Nguyen, G. F. Ross, C. L. Dent, and P. Devarajan, "Early prediction of acute renal injury using urinary proteomics," American Journal of Nephrology, vol. 25, no. 4, pp. 318-326, 2005.

[110] M. T. Nguyen, C. L. Dent, G. F. Ross et al., "Urinary aprotinin as a predictor of acute kidney injury after cardiac surgery in children receiving aprotinin therapy," Pediatric Nephrology, vol. 23, no. 8, pp. 1317-1326, 2008.

[111] J. Metzger, T. Kirsch, E. Schiffer et al., "Urinary excretion of twenty peptides forms an early and accurate diagnostic pattern of acute kidney injury," Kidney International, vol. 78, no. 12, pp. 1252-1262, 2010.

[112] F. Aregger, C. Pilop, D. E. Uehlinger et al., "Urinary proteomics before and after extracorporeal circulation in patients with and without acute kidney injury," Journal of Thoracic and Cardiovascular Surgery, vol. 139, no. 3, pp. 692-700, 2010.

[113] F. Aregger, D. E. Uehlinger, J. Witowski et al., "Identification of IGFBP-7 by urinary proteomics as a novel prognostic marker in early acute kidney injury," Kidney International, vol. 85, no. 4, pp. 909-919, 2014.

[114] M. Bell, A. Larsson, P. Venge, R. Bellomo, and J. Mårtensson, "Assessment of cell-cycle arrest biomarkers to predict early and delayed acute kidney injury," Disease Markers, vol. 2015, Article ID 158658, 9 pages, 2015.

[115] Y. Zhang, Y. Zhang, J. Adachi et al., "MAPU: max-planck unified database of organellar, cellular, tissue and body fluid proteomes," Nucleic Acids Research, vol. 35, supplement 1, pp. D771-D779, 2007.

[116] S.-J. Li, M. Peng, H. Li et al., "Sys-BodyFluid: a systematical database for human body fluid proteome research," Nucleic Acids Research, vol. 37, supplement 1, pp. D907-D912, 2009.

[117] J. Siwy, W. Mullen, I. Golovko, J. Franke, and P. Zürbig, "Human urinary peptide database for multiple disease biomarker discovery," Proteomics-Clinical Applications, vol. 5, no. 5-6, pp. 367374, 2011.

[118] T. M. Shiju, V. Mohan, M. Balasubramanyam, and P. Viswanathan, "Soluble CD36 in plasma and urine: a plausible prognostic marker for diabetic nephropathy," Journal of Diabetes and its Complications, vol. 29, pp. 400-406, 2015.

[119] J. Ma, X. Chen, J.-S. Li et al., "Upregulation of podocyte-secreted angiopoietin-like-4 in diabetic nephropathy," Endocrine, vol. 49, no. 2, pp. 373-384, 2014. 
[120] A. Caseiro, A. Barros, R. Ferreira et al., "Pursuing type 1 diabetes mellitus and related complications through urinary proteomics," Translational Research, vol. 163, no. 3, pp. 188-199, 2014.

[121] I. Zubiri, M. Posada-Ayala, A. Sanz-Maroto et al., "Diabetic nephropathy induces changes in the proteome of human urinary exosomes as revealed by label-free comparative analysis," Journal of Proteomics, vol. 96, pp. 92-102, 2014.

[122] K. Inoue, J. Wada, J. Eguchi et al., "Urinary Fetuin-A is a novel marker for diabetic nephropathy in type 2 diabetes identified by lectin microarray," PLoS ONE, vol. 8, no. 10, Article ID e77118, 2013.

[123] B. Surin, E. Sachon, J.-P. Rougier et al., "LG3 fragment of endorepellin is a possible biomarker of severity in IgA nephropathy," Proteomics, vol. 13, no. 1, pp. 142-152, 2013.

[124] J. Lopez-Hellin, C. Cantarell, L. Jimeno et al., "A form of apolipoprotein A-I is found specifically in relapses of focal segmental glomerulosclerosis following transplantation," American Journal of Transplantation, vol. 13, no. 2, pp. 493-500, 2013.

[125] N. Piyaphanee, Q. Ma, O. Kremen et al., "Discovery and initial validation of $\alpha 1$-B glycoprotein fragmentation as a differential urinary biomarker in pediatric steroid-resistant nephrotic syndrome," Proteomics-Clinical Applications, vol. 5, no. 5-6, pp. 334-342, 2011.

[126] E. O. Honkanen, A.-M. Teppo, and C. Grönhagen-Riska, "Decreased urinary excretion of vascular endothelial growth factor in idiopathic membranous glomerulonephritis," Kidney International, vol. 57, no. 6, pp. 2343-2349, 2000.

[127] A. J. W. Branten, P. W. du Buf-Vereijken, I. S. Klasen et al., "Urinary excretion of beta2-microglobulin and IgG predict prognosis in idiopathic membranous nephropathy: a validation study," Journal of the American Society of Nephrology, vol. 16, no. 1, pp. 169-174, 2005.

[128] T. Nakatsue, H. Koike, G. D. Han et al., "Nephrin and podocin dissociate at the onset of proteinuria in experimental membranous nephropathy," Kidney International, vol. 67, no. 6, pp. 2239-2253, 2005.

[129] C. R. Parikh, J. Mishra, H. Thiessen-Philbrook et al., "Urinary IL-18 is an early predictive biomarker of acute kidney injury after cardiac surgery," Kidney International, vol. 70, no. 1, pp. 199-203, 2006.

[130] W. K. Han, G. Wagener, Y. Zhu, S. Wang, and H. T. Lee, "Urinary biomarkers in the early detection of acute kidney injury after cardiac surgery," Clinical Journal of the American Society of Nephrology, vol. 4, no. 5, pp. 873-882, 2009.

[131] J. Mishra, C. Dent, R. Tarabishi et al., "Neutrophil gelatinaseassociated lipocalin (NGAL) as a biomarker for acute renal injury after cardiac surgery," The Lancet, vol. 365, no. 9466, pp. 1231-1238, 2005.

[132] V. S. Vaidya, V. Ramirez, T. Ichimura, N. A. Bobadilla, and J. V. Bonventre, "Urinary kidney injury molecule-1: a sensitive quantitative biomarker for early detection of kidney tubular injury," The American Journal of Physiology-Renal Physiology, vol. 290, no. 2, pp. F517-F529, 2006.

[133] G. Ramesh, C. D. Krawczeski, J. G. Woo, Y. Wang, and P. Devarajan, "Urinary netrin-1 is an early predictive biomarker of acute kidney injury after cardiac surgery," Clinical Journal of the American Society of Nephrology, vol. 5, no. 3, pp. 395-401, 2010.

[134] P. Devarajan, C. D. Krawczeski, M. T. Nguyen, T. Kathman, Z. Wang, and C. R. Parikh, "Proteomic identification of early biomarkers of acute kidney injury after cardiac surgery in children," American Journal of Kidney Diseases, vol. 56, no. 4, pp. 632-642, 2010.

[135] L. E. Morales-Buenrostro, O. I. Salas-Nolasco, J. BarreraChimal et al., "Hsp72 is a novel biomarker to predict acute kidney injury in critically ill patients," PLoS ONE, vol. 9, no. 10, Article ID e109407, 2014. 

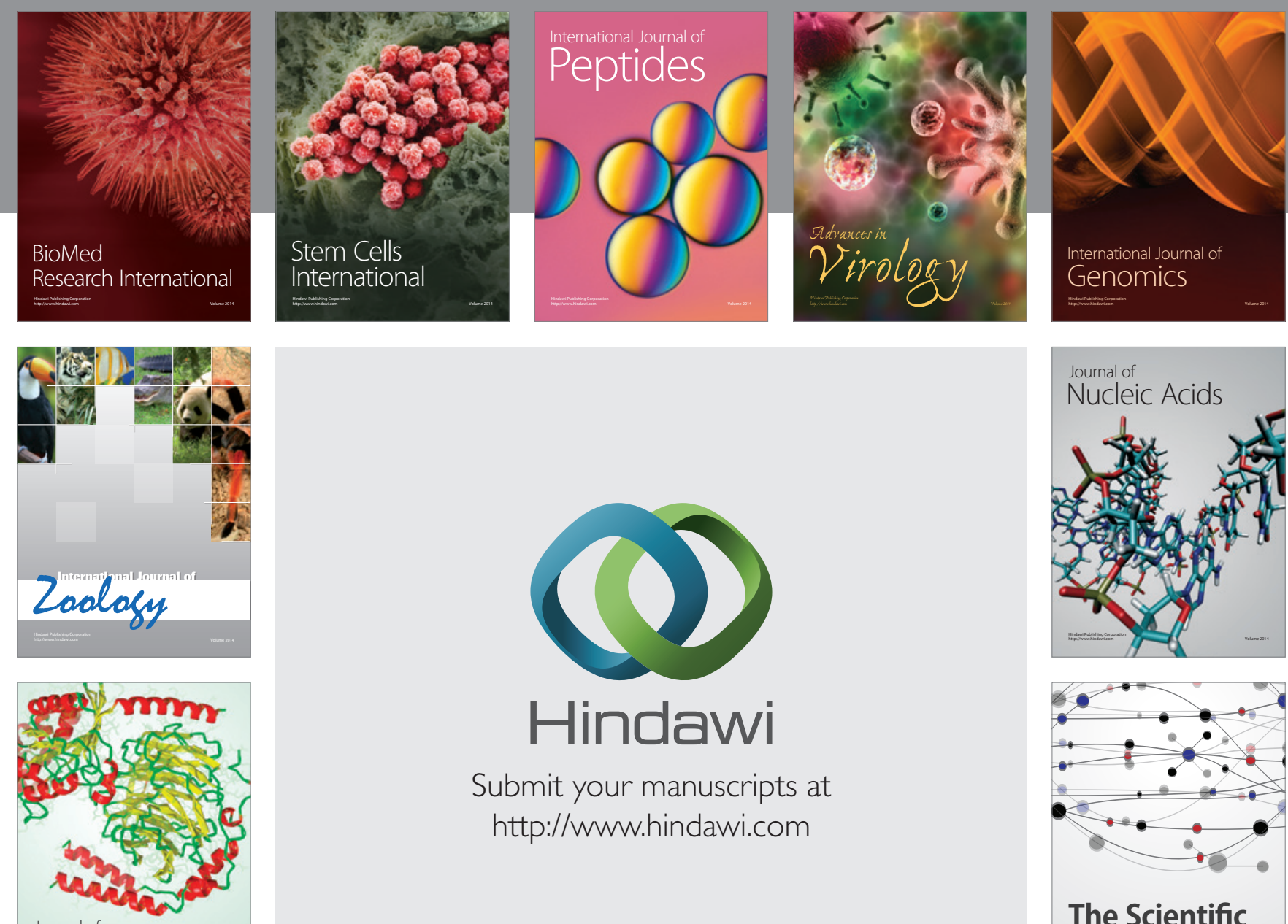

Submit your manuscripts at

http://www.hindawi.com

Journal of
Signal Transduction
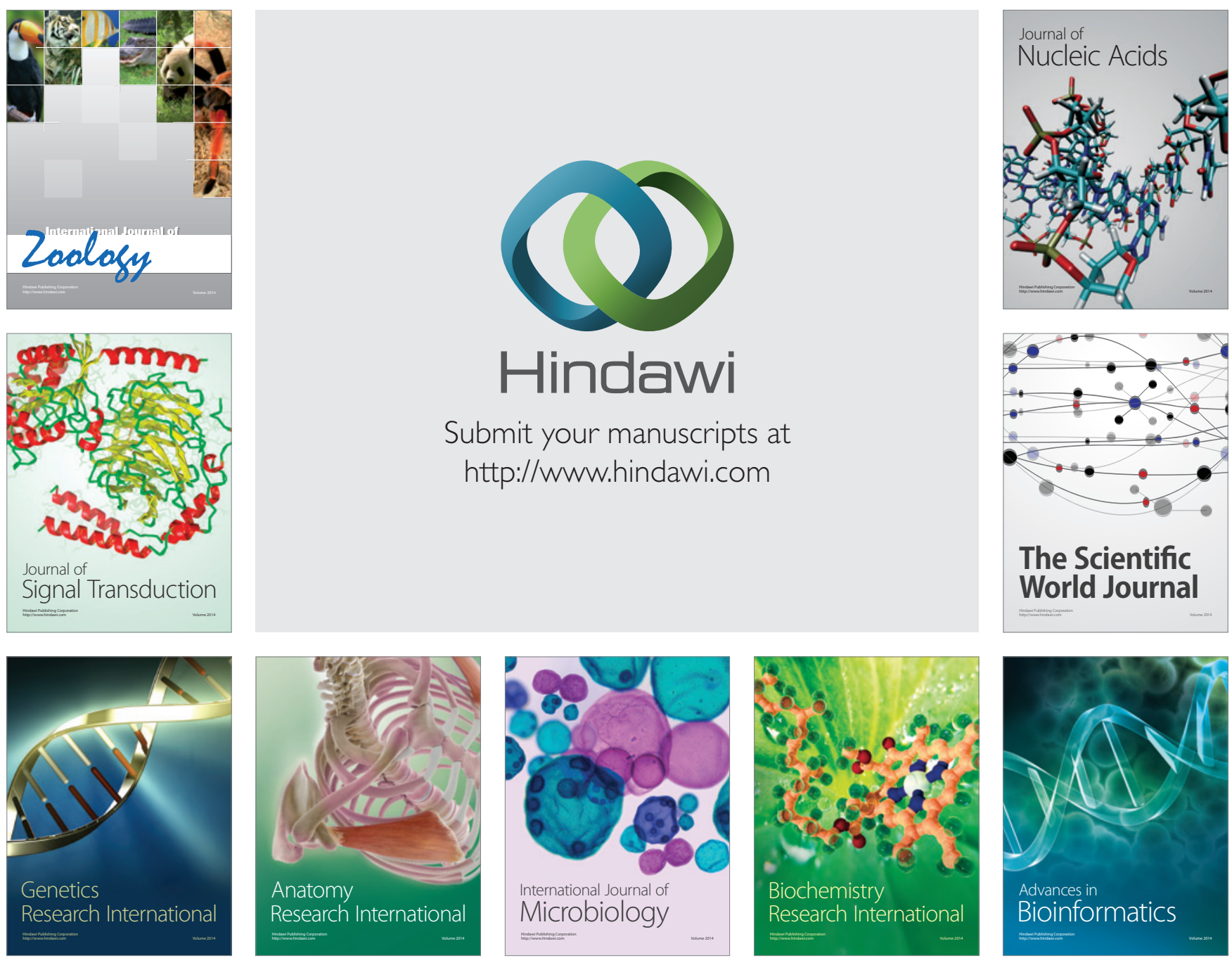

The Scientific World Journal
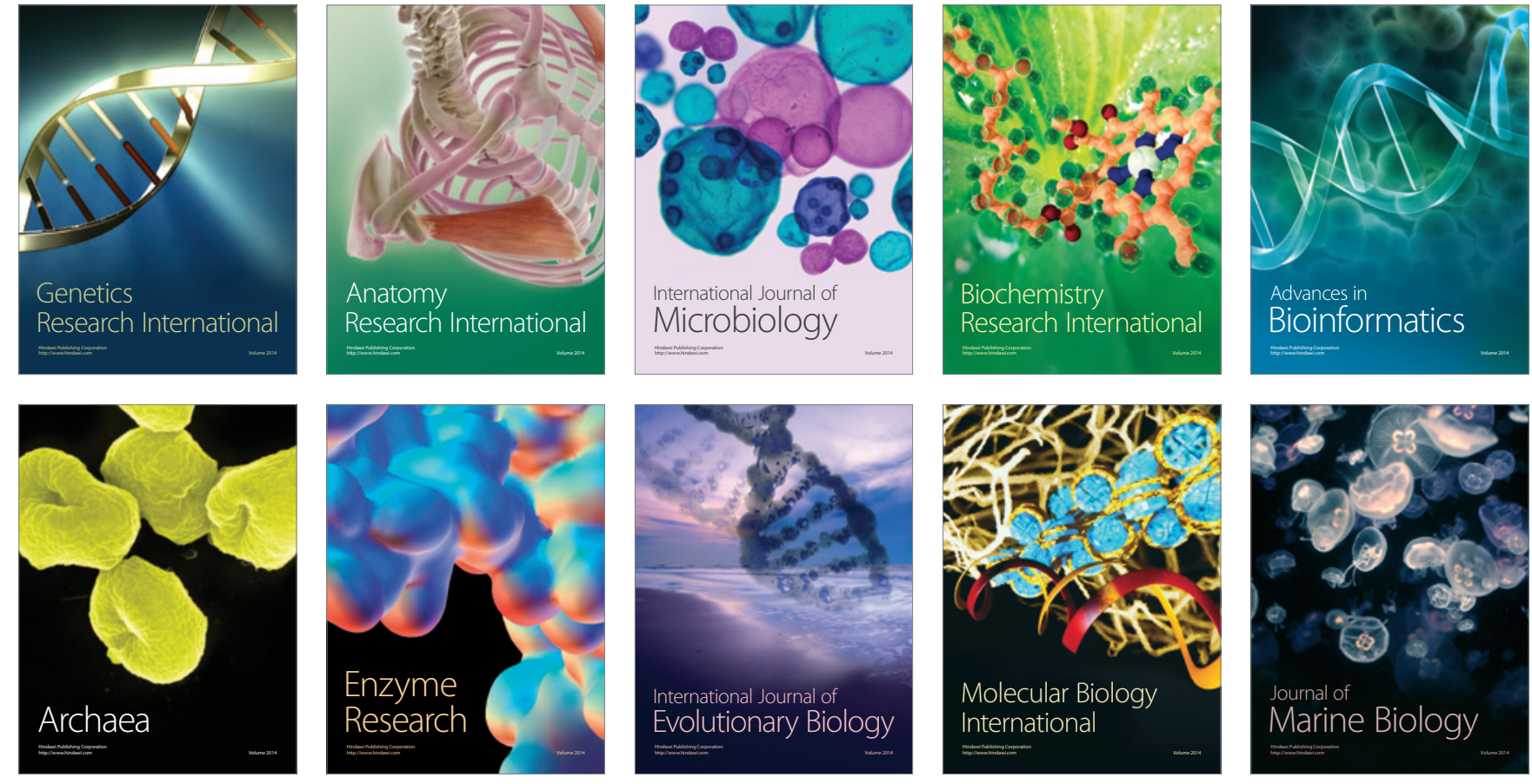